\title{
Spiral Ganglion Degeneration and Hearing Loss as a Consequence of Satellite Cell Death in Saposin B-Deficient Mice
}

\author{
Omar Akil, ${ }^{1}$ Ying Sun, ${ }^{2,4}$ Sarath Vijayakumar, ${ }^{5}$ Wujuan Zhang, ${ }^{3}$ Tiffany Ku, ${ }^{1}{ }^{\mathbb{C}}$ Chi-Kyou Lee, ${ }^{1}$ Sherri Jones, ${ }^{5}$ \\ Gregory A. Grabowski, ${ }^{2,4,6}$ and DLawrence R. Lustig ${ }^{7}$ \\ ${ }^{1}$ Department of Otolaryngology, Head \& Neck Surgery, University of California San Francisco, San Francisco, California 94143-0449, ${ }^{2}$ Division of Human \\ Genetics, ${ }^{3}$ Division of Pathology, Cincinnati Children's Hospital Medical Center, Cincinnati, Ohio 45229-3039, ${ }^{4}$ Department of Pediatrics, University of \\ Cincinnati College of Medicine, Cincinnati, Ohio 45229-3039, ${ }^{5}$ Department of Special Education \& Communication Disorders, School of Veterinary and \\ Biomedical Sciences, University of Nebraska-Lincoln, Lincoln, Nebraska 68583-0738, ${ }^{6}$ Synageva BioPharma Corporation, Lexington, Massachusetts 02421, \\ and ${ }^{7}$ Department of Otolaryngology-Head \& Neck Surgery, Columbia University Medical Center, New York, New York 10032
}

Saposin B (Sap B) is an essential activator protein for arylsulfatase A in the hydrolysis of sulfatide, a lipid component of myelin. To study Sap B's role in hearing and balance, a Sap B-deficient $\left(\mathrm{B}^{-1-}\right)$ mouse was evaluated. At both light and electron microscopy (EM) levels, inclusion body accumulation was seen in satellite cells surrounding spiral ganglion (SG) neurons from postnatal month 1 onward, progressing into large vacuoles preceding satellite cell degeneration, and followed by SG degeneration. EM also revealed reduced or absent myelin sheaths in SG neurons from postnatal month 8 onwards. Hearing loss was initially seen at postnatal month 6 and progressed thereafter for frequency-specific stimuli, whereas click responses became abnormal from postnatal month 13 onward. The progressive hearing loss correlated with the accumulation of inclusion bodies in the satellite cells and their subsequent degeneration. Outer hair cell numbers and efferent function measures (distortion product otoacoustic emissions and contralateral suppression) were normal in the $\mathrm{B}^{-I-}$ mice throughout this period. Alcian blue staining of SGs demonstrated that these inclusion bodies corresponded to sulfatide accumulation. In contrast, changes in the vestibular system were much milder, but caused severe physiologic deficits. These results demonstrate that loss of Sap B function leads to progressive sulfatide accumulation in satellite cells surrounding the SG neurons, leading to satellite cell degeneration and subsequent SG degeneration with a resultant loss of hearing. Relative sparing of the efferent auditory and vestibular neurons suggests that alternate glycosphingolipid metabolic pathways predominate in these other systems.

Key words: auditory; cochlea; prosaposin; saposin B; spiral ganglion; sulfatide

\section{Introduction}

Saposins (Sap) are a family of four small glycoproteins, termed Sap A-D, that are generated in lysosomes from a single precursor protein, prosaposin (Kishimoto et al., 1992). Genetic deficiencies of individual Saps or the precursor prosaposin lead to lysosomal storage diseases, highlighting their physiological importance in glycosphingolipid (GSL) degradation (Hulková et al., 2001; Matsuda et al., 2004). Each of the four Saps is necessary for the activity of one or more lysosomal GSL hydrolases (Sun et al., 2002).

\footnotetext{
Received Aug. 29, 2013; revised Jan. 5, 2015; accepted Jan. 6, 2015.

Author contributions: 0.A. and L.R.L. designed research; 0.A., Y.S., S.V., C.-K.L., W.Z., T.K., S.J., G.A.G., and L.R.L. performed research; 0.A., Y.S., S.V., C.-K.L., W.Z., S.J., G.A.G., and L.R.L. analyzed data; 0.A., Y.S., S.V., and L.R.L. wrote the paper.

This work was supported by Hearing Research Inc. (0.A. and L.R.L.) and Nebraska Tobacco Settlement Biomedical Research Development Funds (S.J.).

The authors declare no competing financial interests.

Correspondence should be addressed to Dr. Lawrence R. Lustig, Department of Otolaryngology/Head \& Neck Surgery, Columbia University Medical Center, 180 Fort Washington Avenue, New York, NY 10032. E-mail: |r|2125@columbia.edu.

DOI:10.1523/JNEUROSCI.3920-13.2015

Copyright $\odot 2015$ the authors $\quad 0270-6474 / 15 / 353263-13 \$ 15.00 / 0$
}

Sap B is a nonenzymatic GSL activator protein that has lipid transfer properties (Ciaffoni et al., 2006) and stimulates the degradation of sulfatide, a major lipid component of myelin, as well as other glycolipids ( $\mathrm{Li}$ et al., 1988). Sap B facilitates partial extraction of target GSLs from membranes, forming soluble protein-lipid complexes and presenting them to arylsulfatase A (ASA) and $\alpha$-galactosidase A, respectively, for cleavage (Ahn et al., 2003).

Loss of ASA activity leads to the human disease metachromatic leukodystrophy (MLD), characterized by accumulation of sulfatides, progressive demyelination, and extensive white matter damage (Von Figura et al., 2001). In mice, targeted disruption of ASA results in diminished in vivo enzyme activity, a resulting accumulation of sulfatide in white matter, and a neurological phenotype without demyelination, including deafness, that manifests by 24 months of age [postnatal month 24 (P24mo); Hess et al., 1996].

Sap B deficiency in humans, caused by a cysteine mutation on Sap B, has been reported in 10 patients involving the fifth cysteine in the Sap B domain. This mutation leads to elevated sulfatide levels in the kidneys and brain, with variable neurological pheno- 
types (Sandhoff, 2001), and a MLD-like disease similar to that observed with ASA deficiency, with lysosomal storage of cerebroside sulfate (Schlote et al., 1991). These mutations include substitutions for critical cysteine residues, insertions, transversions or obliteration of a glycosylation site (Deconinck et al., 2008). Hearing loss and vestibular dysfunction in patients with variant form MLD have not been documented.

A mouse model of Sap B deficiency was previously generated by introducing a point mutation into the Sap B domain of prosaposin, destroying one of the three essential disulfide bonds of Sap B (Sun et al., 2008). This mutation led to an unstable and undetectable Sap B protein, but preserved prosaposin and Sap A, $\mathrm{C}$, and D processing and function. Similar to human patients (Sandhoff, 2001), these Sap B ${ }^{-/-}$mice mimicked the biochemistry and phenotype of the human disease and developed neurological impairment, including ataxia, head tremor, impaired neuromotor coordination, and neuronal storage of sulfatide in their auditory neurons (Sun et al., 2008). However, in contrast to the detailed study of hearing in ASA-deficient mice, no detailed study has been reported of the effect of this Sap B mutation on the hearing and balance in Sap B-deficient mice. The objective of this report is thus to fully characterize the auditory phenotype in the Sap $\mathrm{B}^{-1-}$ mouse, providing insight into Sap B's role in hearing and balance, and also to assess possible differences in function between ASA and Sap B.

\section{Materials and Methods}

\section{Animals}

C57BL/6J Sap B KO $\left(\mathrm{B}^{-1-}\right)$ mice were provided by Dr. Gregory A. Grabowski of the Cincinnati Children's Hospital Medical Center, Cincinnati, Ohio, and backcrossed to an FVB (Friend leukemia virus, strain B) strain (a strain with minimal auditory deficits) to the $10^{\text {th }}$ generation. These mice are termed $\mathrm{B}^{-1-}\left(\operatorname{sapB}^{\mathrm{C} 240 \mathrm{~F} / \mathrm{C} 240 \mathrm{~F}}\right)$ and Het (sapB $\left.{ }^{\mathrm{C} 240 \mathrm{~F} / \mathrm{wt}}\right)$. Both males and females were randomly used on all experiments. The general and CNS phenotype of this $\mathrm{B}^{-1-}$ mouse have been previously described (Sun et al., 2008). All procedures and animal handling were done according to approved national ethical guidelines and complied with all protocol requirements of the University of California San Francisco Institutional Animal Care and Use Committee.

\section{Auditory testing}

Hearing tests were performed as previously described (Akil et al., 2006) with the $\mathrm{B}^{-1-}$ mice, heterozygote (Het), and wild-type (WT) littermates at different ages (P1mo-P15mo). Briefly, all auditory testing was performed in a sound-proof chamber. Before acoustic testing, mice were anesthetized by intraperitoneal injection of a mixture of ketamine hydrochloride (Ketaset, $100 \mathrm{mg} / \mathrm{ml}$ ) and xylazine hydrochloride (xyla-ject, 10 $\mathrm{mg} / \mathrm{ml}$ ) and boosted with one-fifth the original dose as required. Body temperature was maintained with a heating pad and monitored with a rectal probe throughout recording.

Auditory brainstem response. The evoked acoustic brainstem response (ABR) thresholds were differentially recorded from the scalp of the mice. Responses were recorded using subdermal needle electrodes at the vertex, below the pinna of the left ear (reference), and below the contralateral ear (ground). The sound stimuli used included clicks ( $5 \mathrm{~ms}$ duration, $31 \mathrm{~Hz}$ ) and tone pips at 8,16 , and $32 \mathrm{kHz}(10 \mathrm{~ms}$ duration, $\cos 2$ shaping, $21 \mathrm{~Hz}$ ). Measurements were recorded using the TDT BioSig III system (Tucker Davis Technologies). For each stimulus, electroencephalographic (EEG) activity was recorded for $20 \mathrm{~ms}$ (at a sampling rate of 25 $\mathrm{kHz}$ ) and filtered $(0.3-3 \mathrm{kHz})$. Waveforms from 512 stimuli were averaged for click responses. Waveforms from 1000 stimuli were examined to identify frequency-specific tone-burst stimuli $(8,16$, and $32 \mathrm{kHz})$. ABR waveforms were recorded in $5 \mathrm{~dB}$ sound pressure level (SPL) intervals down from the maximum amplitude. The threshold was defined as the lowest stimulus level at which response peaks for waves I-V were clearly and repetitively present upon visual inspection. These threshold judgments were confirmed by analysis of stored waveforms. Data were ob- tained from the WT $(n=15), \mathrm{B}^{-l-}(n=10)$, and Het $(n=12)$ mice littermates.

The comparison of each group of animals was performed using oneway ANOVA with Bonferroni's post hoc testing. Significance was defined at $p<0.05$. To compare the change of ABR latencies, the ABR peaks and troughs were identified automatically by cursers programmed to identify each peak using the Tucker-Davis Technologies system software, and then verified by visual inspection of the recorded wave forms. Latencies were calculated from the onset of the stimulus, and the interpeak latency calculated by subtraction of wave II-I (P2 - P1). The change of the interpeak latency was then calculated. Due to the reduction in the auditory neurons, wave I amplitude analysis was done by peak-to-peak measurement at different intensity levels $(86,76,66$, and $56 \mathrm{~dB}$ SPL) of the stored click ABR waveforms.

Distortion product otoacoustic emissions. The distortion product otoacoustic emissions (DPOAEs) were measured using an acoustic probe placed in the left external auditory canal. Stimuli consisted of two primary tones (f1/f2 $=1.25$ ) digitally synthesized at $100 \mathrm{kHz}$ using SigGen software. The primary tones with geometric mean $(\mathrm{GM})$ frequencies ranging from 6 to $32 \mathrm{kHz}$ and with equal levels $(\mathrm{L} 1=\mathrm{L} 2=60 \mathrm{~dB} \mathrm{SPL})$ were presented via two separate speakers (EC1; Tucker Davis Technologies) to the acoustic probe. DPOAE $2 \mathrm{f} 1-\mathrm{f} 2$ responses were recorded using an ER-10B + (Etymotics Research) microphone assembly within the acoustic probe and the Tucker Davis Technologies BioSig III system. Responses were amplified, digitally sampled at $100 \mathrm{kHz}$, and averaged over 50 discrete spectra. Fast Fourier transforms were computed from averaged responses. For each stimulus set, the DPOAE amplitude level at 2f1-f2 was extracted, and SPLs for data points $100 \mathrm{~Hz}$ above and below the DPOAE frequency were averaged for the noise floor measurements. DPOAE levels were plotted as a function of primary tone GM frequency. Statistical analysis was done using ANOVA with Bonferroni's post hoc tests with significance defined as $p<0.05$. Data were collected from mice at varying ages, including $\mathrm{P} 4 \mathrm{mo}$ and $\mathrm{P} 8 \mathrm{mo}$ for WT $(n=6), \mathrm{B}^{-1-}(n=9)$, and Het $(n=8)$ mice.

Contralateral suppression of DPOAEs. Contralateral suppression of DPOAEs (CS-DPOAEs) was performed using the same software as previously described (Jacobson et al., 2003) with different GM frequencies ranging from 8 to $32 \mathrm{kHz}$. Stimuli were digitally synthesized at $200 \mathrm{kHz}$ using SigGen software applications with the ratio of frequency 2 (F2) to frequency 1 (F1) constant at 1.25; L1 was equal to $65 \mathrm{~dB}$ SPL and L2 was equal to $55 \mathrm{~dB}$ SPL as calibrated in a $0.1 \mathrm{ml}$ coupler simulating the mouse ear canal. Wide-band noise synthesized by the Tucker Davis Technologies Real-Time Processor Video Design Studio software module was set to $55 \mathrm{~dB}$ SPL for each mouse. Stimulus probe and microphone were placed in the test ear or the coupler and the speaker for the contralateral noise source was placed into the opposite ear canal close to the tympanic membrane. Three to four different trials of DPOAEs were acquired and gathered under two different stimulus conditions: in quiet and with contralaterally applied wideband noise. Contralateral suppression magnitude was defined and calculated as distortion product level with contralateral noise-distortion product level in quiet and negative values indicate efferent suppression. Three to four different sets of test results for each animal were averaged and used for statistical difference analysis between WT $(n=6), \mathrm{B}^{-1-}(n=9)$, and Het $(n=8)$ mice littermates using either Student's $t$ test or Mann-Whitney test with significance defined as $p<0.04$.

\section{Cochlea section immunofluorescence}

$\mathrm{B}^{-1-}$ and WT mice littermates at P6mo were anesthetized and their cochleae were isolated, dissected, perfused through the oval and round windows by $4 \%$ paraformaldehyde (PFA) in $0.1 \mathrm{M}$ phosphate buffer (PB), $\mathrm{pH} 7.4$, and incubated in the same fixative for $2 \mathrm{~h}$. After fixation, cochleae were rinsed with $\mathrm{PB}$ and immersed in 5\% EDTA in $0.1 \mathrm{M} \mathrm{PB}$ for decalcification. When cochleae were totally decalcified ( $2-3 \mathrm{~d})$, they were incubated overnight in $30 \%$ sucrose for cryoprotection. The cochleae then were embedded in O.C.T. Tissue Tek Compound (Miles Scientific). Tissues were cryosectioned parallel to the modiolus at $10-12 \mu \mathrm{m}$ thickness for immunofluorescence and for alcian blue stain, mounted on Superfrost microscope slides (Erie Scientific), and stored at $-20^{\circ} \mathrm{C}$ until use. 
For immunofluorescent staining of $\mathrm{B}^{-/-}$and WT cochlea sections, a rabbit anti-neurofilament-200 polyclonal antibody (NF-200; Millipore Bioscience Research Reagents), which labels afferent and efferent auditory fibers (Berglund and Ryugo, 1991), was used in this study. After incubation at $37^{\circ} \mathrm{C}$ for $30 \mathrm{~min}$, the sections were rinsed twice for $10 \mathrm{~min}$ in $0.1 \mathrm{M}$ PBS, pH 7.4, and then preincubated for $1 \mathrm{~h}$ in a humid chamber with blocking buffer and then incubated overnight at $4{ }^{\circ} \mathrm{C}$ with the primary antibody NF-200 diluted in the blocking buffer to 1:500. The slides were then rinsed (twice for $10 \mathrm{~min}$ ) and incubated for $2 \mathrm{~h}$ in goat antirabbit IgG conjugated to Cy2 diluted to 1:2000. Following the removal of the secondary antibodies and before the final washes, the sections were exposed for $15 \mathrm{~min}$ at room temperature to a fluorescent dye $4^{\prime}, 6^{\prime}$ diamidino-2-phenylindole dihydrochloride (DAPI; $1.5 \mu \mathrm{g} / \mathrm{ml}$ in PBS; Sigma-Aldrich). DAPI staining enabled visualization of the nuclei together with immunofluorescence. The sections were rinsed in PBS (twice for $10 \mathrm{~min}$ ) and mounted in equal parts glycerol/PBS and coverslipped. The slides were then observed with an Olympus microscope with confocal immunofluorescence.

\section{Cochlea whole-mount immunofluorescence}

$\mathrm{B}^{-1-}$ mouse cochleae were perfused with $4 \%$ PFA in $0.1 \mathrm{M}$ PBS, pH 7.4, and kept in the fixative for $2 \mathrm{~h}$ at $4^{\circ} \mathrm{C}$. Cochleae were washed with PBS three times for $10 \mathrm{~min}$ and then decalcified with 5\% EDTA in $0.1 \mathrm{M} \mathrm{PBS}$ for $2 \mathrm{~d}$. Following decalcification, the otic capsule was then removed, followed by removal of the lateral wall, Reissner's membrane, and the tectorial membrane. The remaining organ of Corti was incubated with the anti-myosin VIIa antibody (a hair-cell-specific marker; 1:50 dilution in PBS; Proteus Biosciences, catalog \#25-6790) and incubated overnight at $4^{\circ} \mathrm{C}$. Whole-mount cochleae were rinsed twice for $10 \mathrm{~min}$ with PBS and then incubated for $2 \mathrm{~h}$ with a goat anti-rabbit IgG antibody conjugated to Cy2 (1:2000 dilution in PBS; Jackson ImmunoResearch, 111165-003). The whole mounts were rinsed in PBS twice for $15 \mathrm{~min}$ and incubated with rhodamine-phalloidin (stock solution of $200 \mathrm{U} / \mathrm{ml}$ methanol, diluted 1:100 in PBS for working solution) for $1 \mathrm{~h}$. Whole mounts were then rinsed with PBS, further microdissected into individual turns for surface preparation, and then exposed for $15 \mathrm{~min}$ at room temperature to the fluorescent DAPI to mark nuclei. The cochlear whole mounts were rinsed in PBS and mounted on glass slides in antifade FluorSave reagent (Calbiochem, 34589). Hair cells in the organ of Corti were visualized under a confocal microscope.

\section{Vestibular testing}

Vestibular evoked potential. Vestibular evoked potential (VsEP) recordings were based on the methods published previously (Jones et al., 1999, 2004; Mock et al., 2011) and are briefly described here. Animals (P15mo; $\mathrm{B}^{-1-}, n=3$; WT, $n=5$ ) were anesthetized with a ketamine/xylazine (18:2 $\mathrm{mg} / \mathrm{ml}$ ) mixture, $7 \mu \mathrm{l}$ per gram body weight, injected intraperitoneally. Core body temperature was maintained at $37.0 \pm 0.2^{\circ} \mathrm{C}$ using a homoeothermic heating pad system (FHC). Vestibular stimuli were delivered by securing the mouse head using a noninvasive head clip to a mechanical shaker (Model ET-132-203, Labworks). Linear acceleration pulses (17 pulses/s, $2 \mathrm{~ms}$ duration) ranging from +6 to $-18 \mathrm{~dB}$ re: 1.0 $\mathrm{g} / \mathrm{ms}$ (where $1 \mathrm{~g}=9.8 \mathrm{~m} / \mathrm{s}^{2}$ ), adjusted in $3 \mathrm{~dB}$ steps were presented to the head in the naso-occipital axis. Subcutaneous needle electrodes were placed posterior to the right pinna and at the right hip for inverting and ground electrodes, respectively. Stainless-steel wire placed subcutaneously at the nuchal crest served as the noninverting electrode. Electroencephelographic activity was amplified $(200,000 \times)$, filtered (300-3000 $\mathrm{Hz}$ ), and digitized (1024 points at $10 \mu \mathrm{s} /$ point). Two hundred fifty-six primary responses were averaged and replicated for each VsEP waveform. A VsEP intensity series was collected beginning at the maximum stimulus level (i.e., $+6 \mathrm{~dB}$ re: $1.0 \mathrm{~g} / \mathrm{ms}$ ) with and without acoustic masking (50-50,000 $\mathrm{Hz}$ forward masker at $90 \mathrm{~dB} \mathrm{SPL})$, and then descending in $3 \mathrm{~dB}$ steps until no response was visible. Thresholds (measured in $\mathrm{dB}$ re: $1.0 \mathrm{~g} / \mathrm{ms}$ ), peak latencies (milliseconds), and peak-to-peak amplitudes (microvolts) were obtained from the VsEP waveforms.

Swimming test. Vestibular function was also assessed with the commonly used test, the swimming test. The data of the swimming test (Lim et al., 1978; Sawada et al., 1994; Ornitz et al., 1998; Jones et al., 1999; Khan et al., 2004) were obtained from $6 \mathrm{WT}$ and $6 \mathrm{~B}^{-/-}$mice at different ages (P4mo, P8mo, and P15mo). Mice were put in a $20 \times 40 \mathrm{~cm}$ Plexiglas cage filled with water at room temperature for $60 \mathrm{~s}$. The average swimming time with the head above water was determined for three trials for each mouse.

\section{Alcian blue staining}

Alcian blue stain, which detects acidic sulfated lipids, was used to demonstrate sulfatide accumulation in cochlea sections. $\mathrm{B}^{-1-}$ and WT mice littermates at P6mo were anesthetized and their cochleae were processed for frozen sections as described above. Sections were rinsed in 3\% acetic acid for $3 \mathrm{~min}$ and stained with alcian blue solution ( $1 \%$ alcian blue in $3 \%$ acetic acid), pH 2.5 (Polyscientific, S111A), for $30 \mathrm{~min}$. After rinsing with $3 \%$ acetic acid followed by water, sections were counterstained with nuclear fast red; slides were then mounted and visualized with a Leica microscope.

\section{Histology}

Light microscopy. $\mathrm{B}^{-1-}$ mice and WT littermates at different ages (P1mo-P15mo) were anesthetized and their cochleae were isolated, dissected, perfused through the round and oval windows with a solution of $2.5 \%$ paraformaldehyde and $1.5 \%$ glutaraldehyde in $0.1 \mathrm{M}$ PB solution, $\mathrm{pH} 7.4$, and finally incubated in the same fixative overnight at $4^{\circ} \mathrm{C}$. The cochleae were rinsed with $0.1 \mathrm{M} \mathrm{PB}$ and postfixed in $1 \%$ osmium tetroxide for $2 \mathrm{~h}$. The cochleae were subsequently immersed in 5\% EDTA for decalcification. The decalcified cochleae were dehydrated with ethanol and propylene oxide and then embedded in Araldite 502 resin (Electron Microscopy Sciences). The cochleae were then sectioned at 1-5 $\mu \mathrm{m}$ thickness parallel to the cochlea modiolus. The sections were stained with toluidine blue and mounted with Permount (Fisher Scientific) on microscope slides and visualized with a Leica microscope.

$E M$. The cochleae of $\mathrm{B}^{-1-}$ and WT mice were surgically exposed, a stapedectomy was performed, and the round window perforated. Temporal bones were preserved by gentle in vivo perfusion of fixative $(2.5 \%$ paraformaldehyde and $1.5 \%$ glutaraldehyde buffered to $\mathrm{pH} 7.4$ with 0.1 M phosphate) through the perilymphatic channels, followed by postfixation with a solution of $1 \%$ osmium tetroxide and $1.5 \%$ potassium ferricyanide phosphate buffered solution (potassium ferricyanide was used to improve contrast). The cochleae were decalcified, dehydrated, and then embedded in Epon. Thick sections $(1 \mu \mathrm{m})$ were mounted onto glass slides and counterstained with toluidine blue. Once the cochlea spiral ganglion (SG) cells were observed, several ultrathin silver-to-gray sections were collected on Formvar films on slotted grids and stained with saturated aqueous $2 \%$ uranyl acetate and $0.4 \%$ lead citrate in $0.15 \mathrm{~N}$ sodium hydroxide. The stained sections were then examined at $60 \mathrm{kV}$ in a JEOL JEM-100S transmission electron microscope.

Cochlea SG cell counts. Cochlea SG cells numerical density assessment was calculated as described by Leake et al. (2011) to accurately estimate the number of nuclei in a given volume of tissue. For this analysis, three sets of three serial sections (5 $\mu \mathrm{m}$ thickness) were collected from the base, midturn, and the apex of $4 \mathrm{WT}$ and $5 \mathrm{~B}^{-1-}$ cochlea. Adjacent serial sections were compared, and new nuclei of SG neurons that appear in the second section were counted. Statistical differences were measured using Student's $t$ test.

\section{Sulfatide and ceramide analysis using liquid chromatography/} tandem mass spectrometry

Synthetic $N$-acyl ceramide standards (C16, C17, C18, C24 Cer) of 99\% purity were from Avanti Lipids. Semisynthetic $\mathrm{N}$-acyl sulfatides (C12, C16, C24 sulfatide) were from Matreya. All other solvents and chemicals of either high-performance liquid chromatography grade or analytical purity were purchased from Sigma-Aldrich. Mouse cochlea SGs dissected from P6mo cochleae of WT and $\mathrm{B}^{-1-}$ mice were homogenized with PowerGen 35 (Fisher Scientific) in methanol/chloroform/water (3.6 $\mathrm{ml}, 2: 1: 0.6, \mathrm{v} / \mathrm{v} / \mathrm{v})$. Homogenates were shaken for $15 \mathrm{~min}$ and centrifuged $(5 \mathrm{~min}$ at $1000 \times g)$. Pellets were re-extracted with $\mathrm{H}_{2} \mathrm{O}(0.7 \mathrm{ml})$ and $3 \mathrm{ml}$ of chloroform/methanol (1:2). The combined extracts were centrifuged $(10 \mathrm{~min}$ at $7000 \times g)$. The supernatants were transferred to fresh tubes and the solvents evaporated under nitrogen gas. Dried samples were then dissolved in chloroform/methanol/water ( $5 \mathrm{ml}, 2: 1: 0.15)$ and subjected 
to alkaline methanolysis followed by eluting from a Sephadex G-25 fine column to remove nonlipid contaminants. The extracted lipids were suspended in methanol containing internal standards for liquid chromatography/mass spectrometry analyses.

Nonhydroxy fatty acid (NFA) sulfatide, hydroxy fatty acid (HFA) sulfatide, and ceramide were determined by liquid chromatography-electrospray ionization-tandem mass spectrometry using a Waters Quattro Micro API triple quadrupole mass spectrometer interfaced with Acquity UPLC system. Online chromatographic separation was achieved using a Thermo Scientific BetaSil C8 column $(100 \times 2.1 \mathrm{~mm}, 5 \mu \mathrm{m})$. The electrospray ionization-tandem mass spectrometry was performed in the multiple-reaction monitoring mode. Sulfatides were analyzed in negative ion mode by detection of their parent ion and common daughter ion of $m / z$ 97. Ceramides were detected with the transition pair of the individual protonated parent ions and their common daughter ion $\mathrm{m} / \mathrm{z} 264$. Optimized parameters for each lipid were determined with individual standard compounds. C16 and C24 sulfatide standards were used to construct calibration curves and C12 sulfatide was used as an internal standard. For ceramide analysis, C16, C18, and C24 ceramides were used for calibration curves and C17 ceramide was used as the internal standard.

\section{Results \\ Light microscopy}

Standard histological analysis was initially used to assess the result from the loss of Sap B function in the $\mathrm{B}^{-1-}$ mouse ears. As expected, in WT control midmodiolar sections, SG neurons were present in normal numbers throughout the cochlea and their light microscopic appearance was unremarkable (Fig. 1A-D, white arrows). In $\mathrm{B}^{-l-}$ mice, the morphology of the organ of Corti was for the most part normal across all genotypes, including normal inner hair cells (IHCs), outer hair cells (OHCs), tectorial membrane, and stria vascularis (Fig. $1 A, B$ ). The most significant finding in the cochleae of $\mathrm{B}^{-1-}$ mice was a severe reduction of SG neurons and cochlear nerve fibers within Rosenthal's canal (Fig. $1 A$ ). The degeneration was notable by $\mathrm{P} 8 \mathrm{mo}$ and progressed through $\mathrm{P} 15 \mathrm{mo}$ (Fig. $1 C$ ). Closer examination at varying time points, including at $\mathrm{P} 1 \mathrm{mo}, \mathrm{P} 2 \mathrm{mo}, \mathrm{P} 4 \mathrm{mo}, \mathrm{P} 6 \mathrm{mo}, \mathrm{P} 8 \mathrm{mo}$, and $\mathrm{P} 15 \mathrm{mo}$ demonstrated abnormal inclusion in the $\mathrm{B}^{-1-}$ satellite cells adjacent to the SG neurons in Rosenthal's canal (Fig. 1C, black arrows). These inclusions in the satellite cells become visible as early as $\mathrm{P} 1 \mathrm{mo}$ in $\mathrm{B}^{-1-}$ mice and increase dramatically with age. In older mice, they can also be seen in the cytoplasm of the SG neuronal cell bodies. These increases in severity of the inclusion bodies are closely associated with the loss of SG neurons in the $\mathrm{B}^{-1-}$ mouse at $\mathrm{P} 6 \mathrm{mo}$ and beyond. By $\mathrm{P} 15 \mathrm{mo}$, the inclusions are greater while the SG cell numbers are severely reduced. The only surviving neurons in the older $\mathrm{B}^{-/-}$mice proved to be small, primarily nonmyelinated type 2 ganglion cells. The small diameter and the absence of a compact myelin sheath served to identify the surviving neurons as type 2 cells (Fig. 1C, P15mo, arrowheads). Figure $1 D$ shows higher-magnification images of the SG cells of normal satellite cells in the WT and increasing inclusion in the satellite cells in the $\mathrm{B}^{-1-}$ mice.

\section{SG neuronal analysis}

At several developmental stages, transverse cochlea sections of WT mice show a normal number of myelinated nerve fibers within the osseous spiral lamina while sections of $\mathrm{B}^{-1-}$ mouse cochlea show a progressive loss of nerve fibers (Fig. 2A). This loss of fibers in the $\mathrm{B}^{-1-}$ mice was further confirmed by immunofluorescence staining of the cochlea cross sections (Fig. 2B) using an anti-neurofilament antibody, a marker of both afferent and efferent neuronal auditory nerves (Berglund and Ryugo, 1991), which demonstrates weaker signal in the $\mathrm{B}^{-l-}$ mouse compared with the WT mouse.
To quantitatively assess the loss of cochlear neuron fibers, counts were made in tangentially sectioned specimens at the cochlea midturn during development (Fig. 2C) in the same region of the cochlea where the transverse cochlea sections were made (Fig. 2A). The average number of myelinated nerves in this specific region was calculated in $100 \mu \mathrm{m}$ segments. These counts demonstrate that the loss of cochlear nerve fibers in the $\mathrm{B}^{-1-}$ mice begins at $\mathrm{P} 4 \mathrm{mo}$ and progresses through $\mathrm{P} 15 \mathrm{mo}$ where only 43 and $15 \%$ of nerve fibers remain, respectively (Fig. 2D). The cochlear Schwann cell counts were done in a similar manner and confirm that the loss of cochlear neuronal fibers is accompanied by the loss of Schwann cells (Fig. 2E). SG cell numerical density, calculated as described by Leake et al. (2011), documents that the total cochlear SG cell loss is similar to the cochlea nerve fiber loss in $\mathrm{B}^{-1-}$ mice, but is variable between cochlea turns (Fig. $2 F$ ): more SG cell loss was seen in the base at P4mo compared with midturns and apical turns. Interestingly, though the overall number of SG neurons was reduced in $\mathrm{B}^{-1-}$ mice, there was a clear increase in the size of individual SG neurons at all ages in the apex and at P15mo for all cochlea turns (Fig. 2G).

\section{EM}

At the ultramicroscopic level, the changes in the SG neurons were even more striking (Fig. 3). As compared with WT mouse SG neurons (Fig. $3 A$ ), $\mathrm{B}^{-1-}$ mouse SG neurons demonstrated marked hypertrophy and accumulation of clear vacuoles in the satellite cells (appearing like fatty particles), resulting in disruption of the normal structure of the SG. Similar to that seen under light microscopy, these inclusions in the satellite cells increased progressively with age and were highly associated with the loss of SG neurons in the $\mathrm{B}^{-1-}$ mouse. By P15mo, the SG neurons were severely reduced in the $\mathrm{B}^{-1-}$ mouse. SG neuronal organelles otherwise appear normal. The myelin sheaths of the cochlear nerve fibers were also analyzed (Fig. $3 B$ ). As shown, by P8mo and onward, there was almost a complete lack of myelin surrounding these neurons, suggesting either a cause or consequence of the SG neuronal degeneration.

\section{Auditory measures}

We next sought to determine the effect of Sap B deficiency on hearing in light of the progressive neuronal degeneration seen in this model. In these studies, ABR was used to test hearing in $\mathrm{B}^{-1-}$, Het, and WT mice at varying ages (P1mo, P3mo, P4mo, P6mo, P8mo, P13mo, and P15mo) using broadband clicks and tone-burst stimuli $(8,16$, and $32 \mathrm{kHz})$. As shown in Figure $4 A$, at P4mo, ABR thresholds demonstrated no significant differences in hearing among the $\mathrm{B}^{-1-}(n=10)$, Het $(n=12)$, and WT mice $(n=15)$. However by P8mo (Fig. $4 B)$ a significant increase in ABR thresholds was observed for each of the tone-burst stimuli $(8,16$, and $32 \mathrm{kHz})$, though not for click stimuli, in $\mathrm{B}^{-1-}$ mice compared with WT and Het mice. For click stimuli, the thresholds of WT versus $\mathrm{B}^{-1-}$ mice did not significantly differ until P13mo (Fig. 4C). In contrast, for pure-tone stimuli, significant threshold shifts are seen as early as P6mo (Fig. 4D; only the 16 $\mathrm{kHz}$ tone is shown). We also noted that at $\mathrm{P} 4 \mathrm{mo}$ there was no significant difference of the ABR wave I amplitude between $\mathrm{B}^{-1-}$ and the WT mice for click stimulus (data not shown). By P8mo, however, $\mathrm{B}^{-1-}$ mice showed a significant decrease of ABR amplitude when compared with the WT littermates (Fig. $4 E$ ), likely as a consequence of the reduction in the auditory neurons.

To analyze whether the demyelination of cochlear fibers seen at the EM level (Fig. 3B) affected ABR wave morphology, the ABR interpeak latency between P1 and P2 was measured at varying 

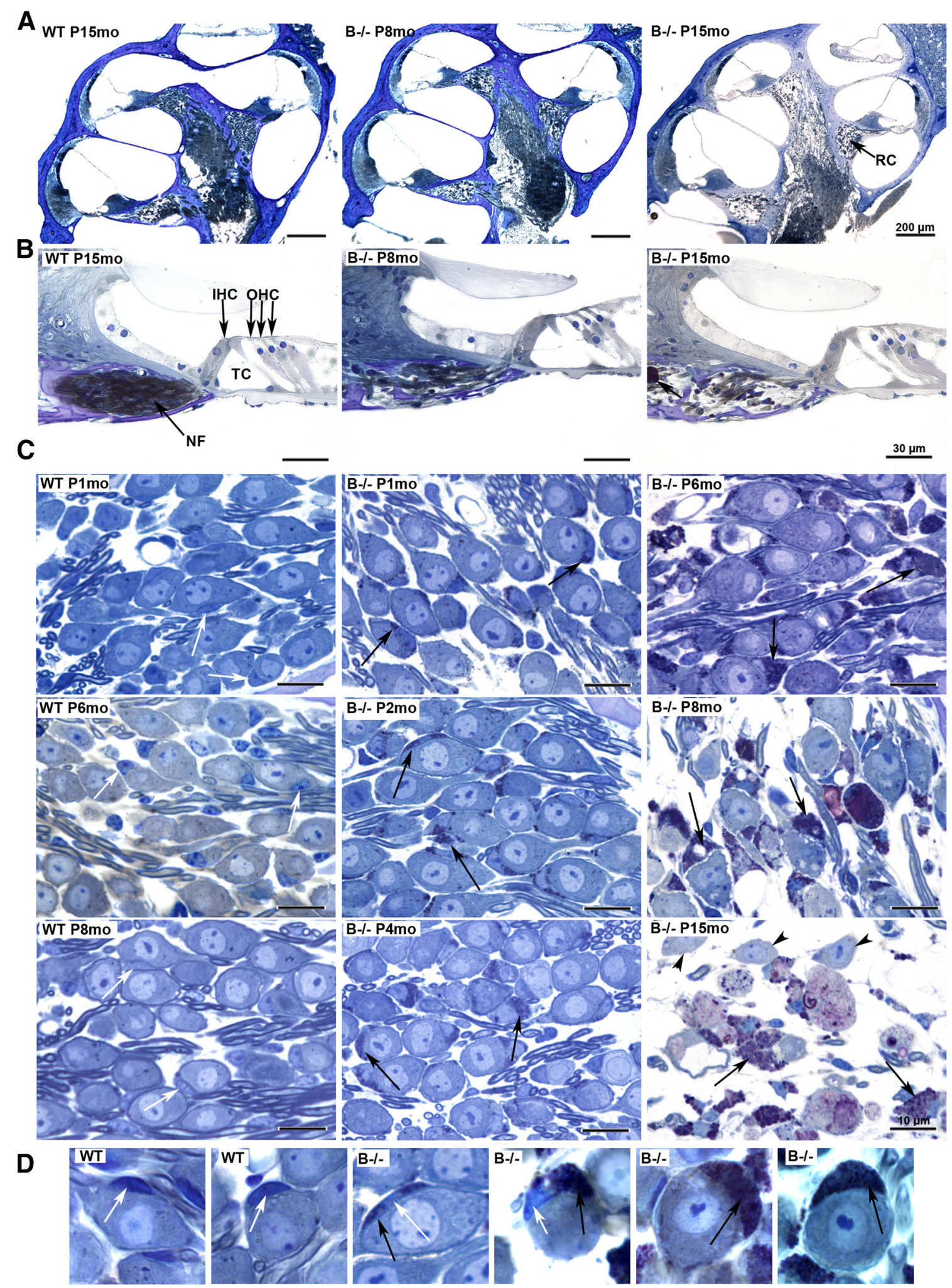

Figure 1. Light microscopy of the cochlea and SG neurons of $B^{-1-}$ mice during development. $A, B$, Cochlea and organ of Corti at low $(\boldsymbol{A})$ and high $(\boldsymbol{B})$ magnification. Rosenthal's canal (RC) is occupied by SG cells and cochlear nerve fibers in the WT (shown at P15mo), while similar views of the $B^{-1-}$ mouse are marked by increasing loss of SG and cochlear nerve fibers at P8mo and P15mo. These images also document normal organ of Corti morphology, including IHCs and $\mathrm{OHCs}$ and the stria vascularis in both WT and $\mathrm{B}^{-1-}$ mice through P15mo. NF, Nerve fibers; TC, tunnel of Corti. Scale bar, $200 \mu \mathrm{m}$. C, Light micrographs of semithin sections $(5 \mu \mathrm{m})$ of SGs of B ${ }^{-1-}$ mice at P1mo, P2mo, P4mo, P6mo, P8mo, and P15mo. WT mice at P1mo, P6mo, and P8mo are included for comparison. Overall morphology between the SGs of the $B^{-1-}$ and the WT mice is similar, but abnormal inclusions in the satellite cells are first seen at P1mo in $B^{-1-}$ mice (black arrow) when compared with normal SGs of WT (white arrow) mice. These inclusions in the satellite cells increase progressively with age (arrows) and are associated with loss of SG neurons in B ${ }^{-1-}$ mice at P6mo and older. At P15mo, nonmyelinated SG type 2 neurons are clearly visualized and normal appearing (arrowheads), whereas myelinated type 1 neurons SG cell numbers are severely reduced in $B^{-1-}$ mice. Scale bar, $10 \mu \mathrm{m}$. D, Magnified view of the SG neurons and surrounding normal satellite cells in WT mice (white arrows) and increasing inclusions in the satellite cells in $B^{-1-}$ mice (black arrows). 

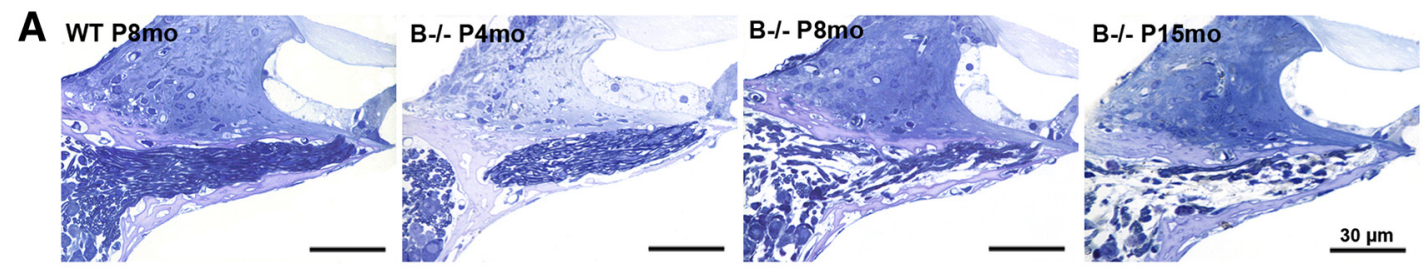

B
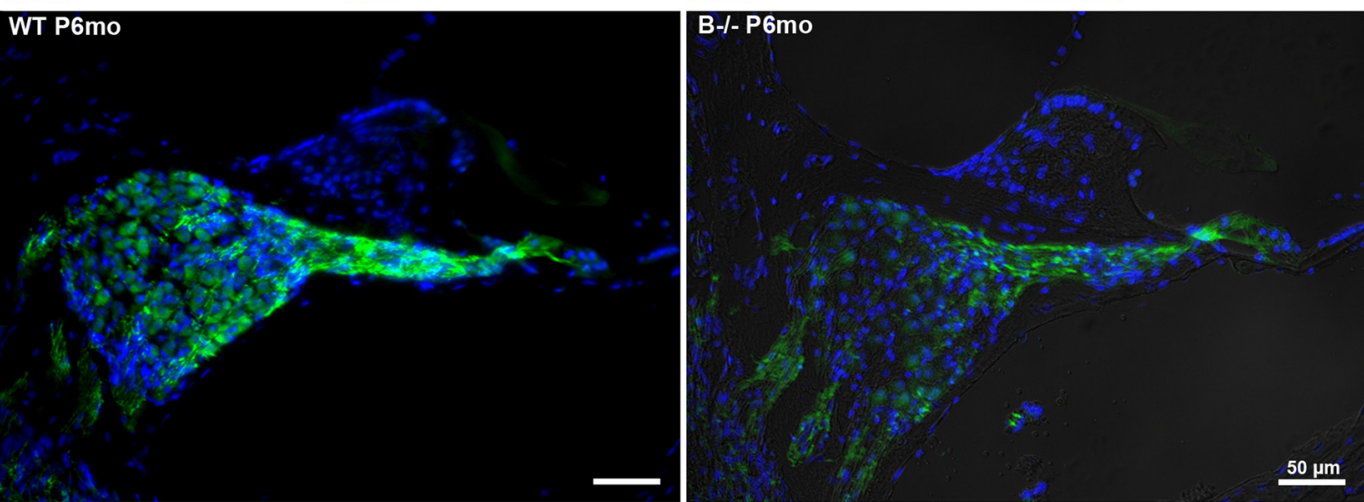

C

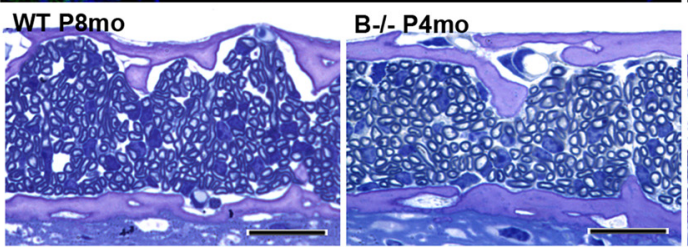

B-I- P8mo

B-I- P15mo

D

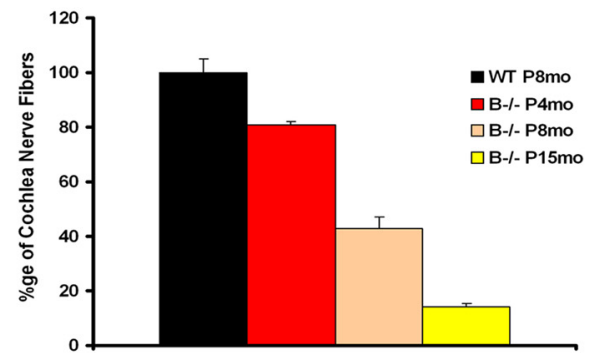

$\mathbf{F}$

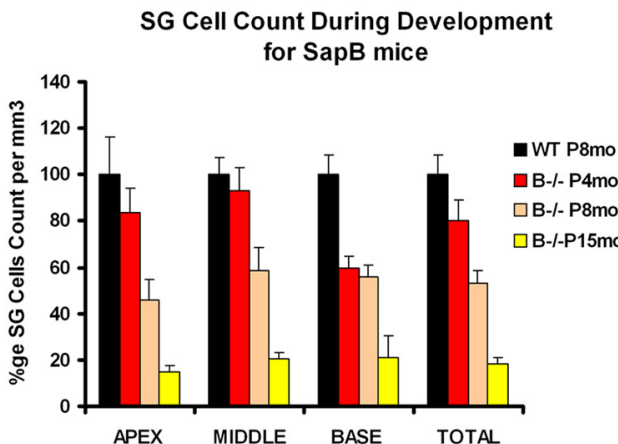

E

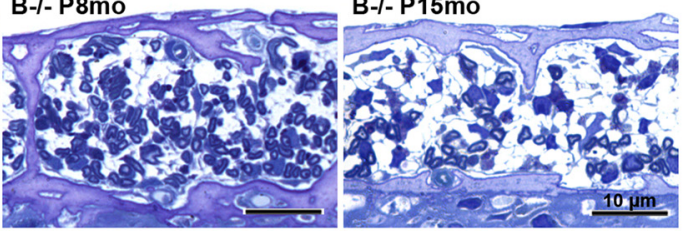

Cochlear Schwann Cells Count During

Development for SapB mice

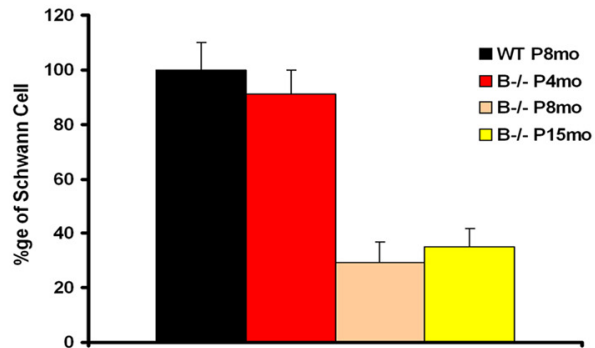

G

SG Cell Size During Development for SapB mice

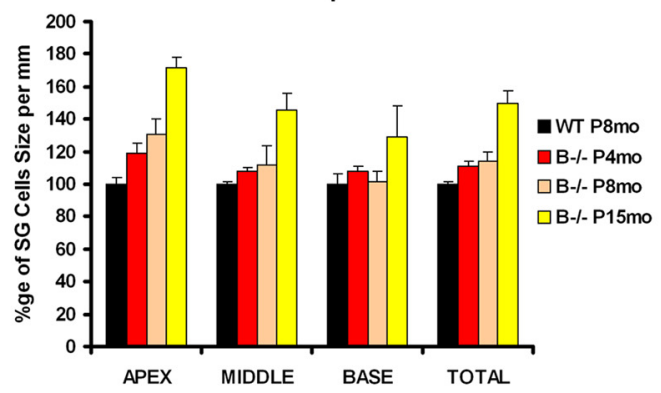

Figure 2. Cochlea $S G$ neurons and nerve fiber assessment in the $B^{-1-}$ mice during development. $A$, Toluidine blue-stained sections of the radial cochlea nerve fibers during development stages show a progressive cochlea fiber loss with age in the $B^{-1-}$ mice when compared with the WT littermates (black arrows). Scale bar, $30 \mu \mathrm{m} . \boldsymbol{B}$, Immunofluorescence of the cochlea nerve fibers with anti-neurofilament antibody (a marker of afferent and efferent neuronal auditory nerves; Berglund and Ryugo, 1991) stain shows that the P6mo $B^{-1-}$ mouse cochlear section has significantly less labeling of the cochlear nerve fibers compared with the WT littermate, documenting the presence of fewer fibers in the $B^{-1-}$ compared with the WT mice. Scale bar, $50 \mu \mathrm{m}$. C, Toluidine blue-stained sections, cut tangentially through the osseous spiral lamina to reveal cochlear nerve fibers in cross section, show a progressive cochlear fiber loss with age in $B^{-1-}$ mice compared with WT littermates, similar to that observed for the radial cochlea nerve fibers in light microscopy $(\boldsymbol{A})$ and immunofluorescence $(\boldsymbol{B})$. Scale bar, $10 \mu \mathrm{m}$. $\boldsymbol{D}$, Quantitative assessment of cochlea nervefiber numbers in $B^{-1-}$ mice during development. Loss of nerve fibers is first documented at $\mathrm{P} 4 \mathrm{mo}$ and increased at $\mathrm{P} 8 \mathrm{mo}$ and $\mathrm{P} 15 \mathrm{mo}$, when only 43 and $15 \%$ of nerve fibers remain, respectively. $E$, The cochlear $S$ chwann cell counts were done in a similar manner and confirm that the loss of cochlear neuronal fibers is accompanied by the loss of Schwann cells at P8mo and at P15mo in B ${ }^{-1-}$ mice. $F$, Quantitative assessment of cochlea SG cell counts through P15mo. The loss of cochlearSG neurons mirrors the loss of cochlea nerve fibers in $\mathrm{B}^{-1-}$ mice. AtP4mo, there was a greater loss of SG neurons in the base compared with the midturns and apical turns, but by $\mathrm{P} 8 \mathrm{mo}$ and beyond no differences in cell counts were noted between turns. G, Though overall SG neuronal counts, Schwann cells, and nerve fibers are reduced (Fig. 2D-F), the SG cell size was significantly increased in the apical turns and midturns of $\mathrm{B}^{-1-}$ mice at $\mathrm{P} 4 \mathrm{mo}$ and $\mathrm{P} 8 \mathrm{mo}$, but at $\mathrm{P} 15 \mathrm{mo}$ this increase in cell size was significant for all cochlear turns. 
A
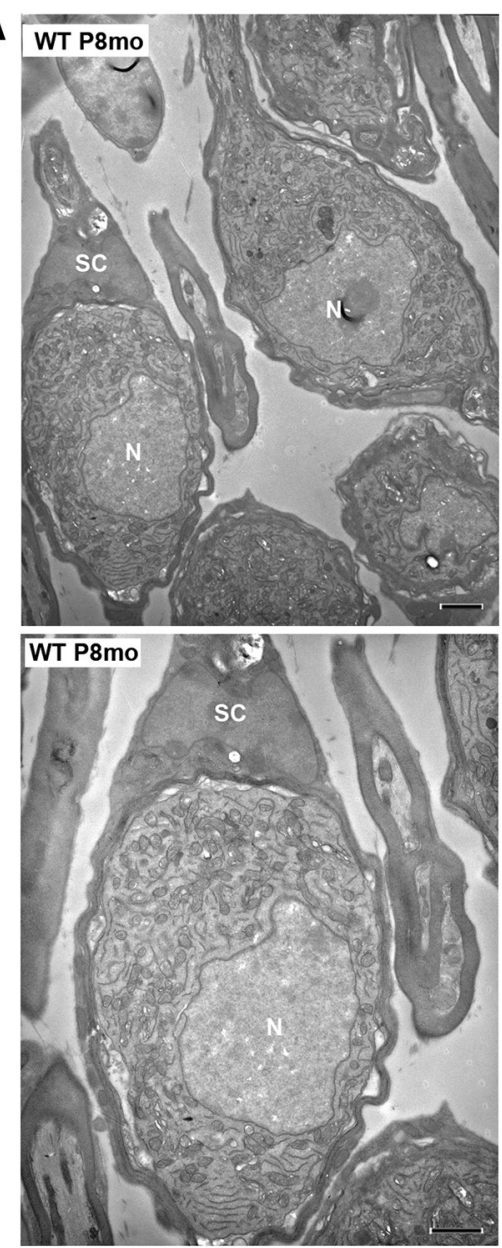

$\mathbf{B}$

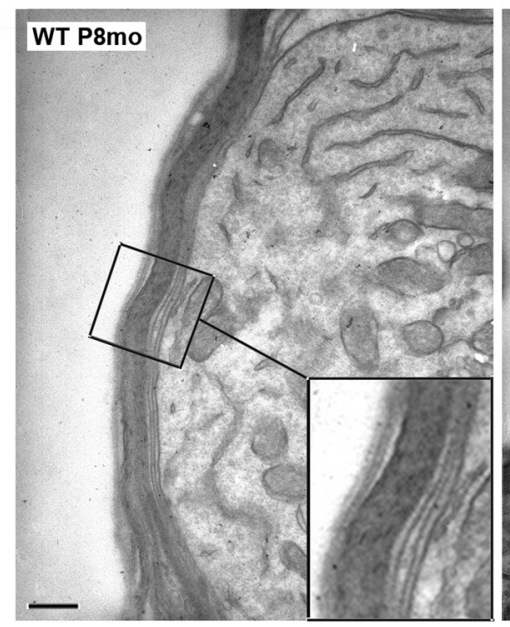

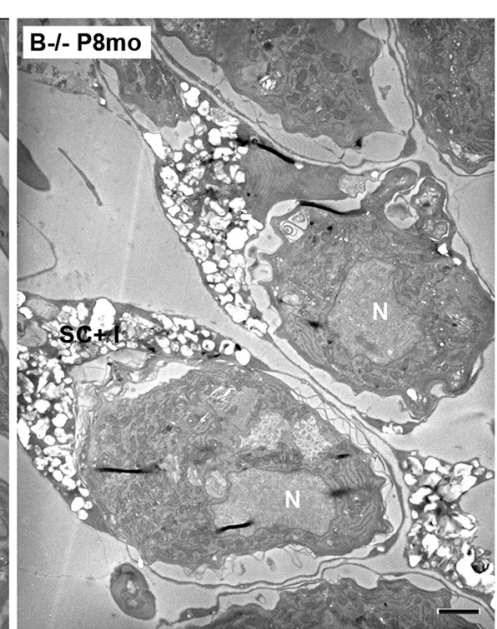
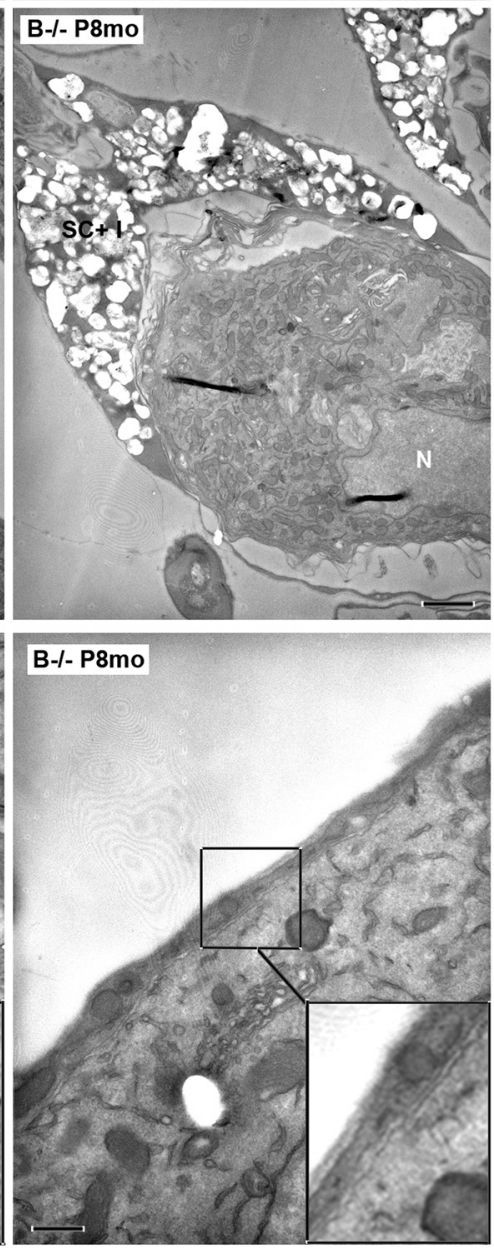
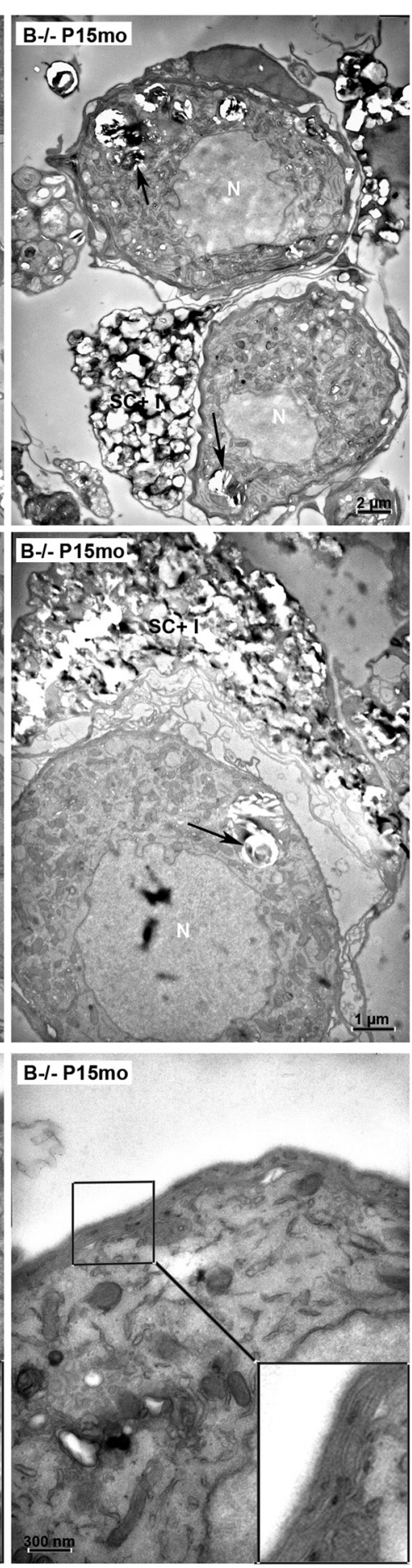

Figure 3. EM of the SG neurons and the myelin sheaths of $\mathrm{B}^{-1-}$ mice. $A, S G$ neurons from WT (P8m0) and B ${ }^{-1-}$ (P8mo and P15mo) mice at lower magnification. Scale bars: top, $2 \mu \mathrm{m}$; bottom, $1 \mu \mathrm{m}$. WT mice demonstrate normal SG morphology (left column). In contrast, inclusions were seen in $B^{-1-}$ mouse ears where satellite cells are packed with lucent material containing inclusion bodies with large vacuoles mixed with large electron dense material. These inclusions in the satellite cells greatly increase in $B^{-1-}$ mice at P15mo. The separation of the myelin sheath from the SG neuron seen in WT mice is likely artifactual, due to specimen processing. N, SG nucleus; SC, satellite cells; SC + I, satellite cells plus inclusions; black arrows, inclusions in SG cytoplasm. B, At P8mo, SG myelin sheaths in $\mathrm{B}^{-I-}$ mice are so thin they seem to disappear. Meanwhile, SG myelin sheaths in the WT littermates at P8mo are clearly visible. Scale bar, $300 \mathrm{~nm}$.

time points. At P4mo, no significant differences in P2-P1 latencies were seen between $\mathrm{B}^{-1-}$ and WT mice for either tone or click stimuli (data not shown). By P8mo however, $\mathrm{B}^{-1-}$ mice demonstrated significant P2-P1 delays for tone stimuli, though not for click stimuli (Fig. $4 F$ ). This decrease in conduction velocity is likely a consequence of the progressive SG demyelination and/or SG neuronal degeneration in $\mathrm{B}^{-1-}$ mice evident at this time period.

\section{$\mathrm{OHC}$ and efferent function of the Sap B mice}

DPOAE and CS tests were performed to evaluate the OHC and efferent neuronal function in $\mathrm{B}^{-1-}$ mice at $\mathrm{P} 4 \mathrm{mo}$ (Fig. $5 \mathrm{~A}, C$ ) and P8mo (Fig. $5 B, D$ ). As shown in Figure $5 A-D$, no significant differences were noted between $\mathrm{B}^{-1-}$ and WT mice DPOAE and CS at P4mo and P8mo, excluding the impairments that are due to a peripheral loss of hair cell function that 
A

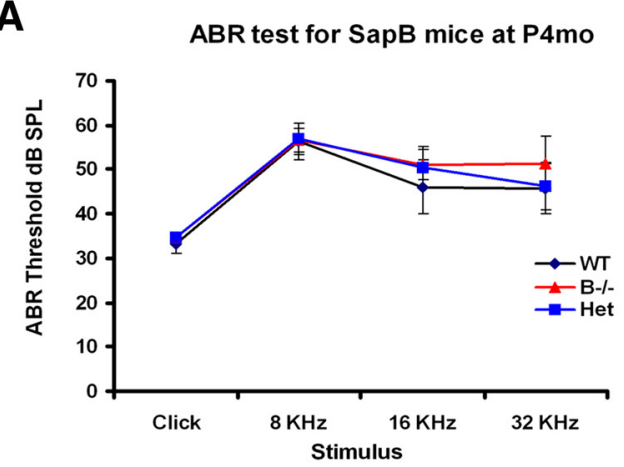

C

ABR Threshold during Development for SapB mice (click)

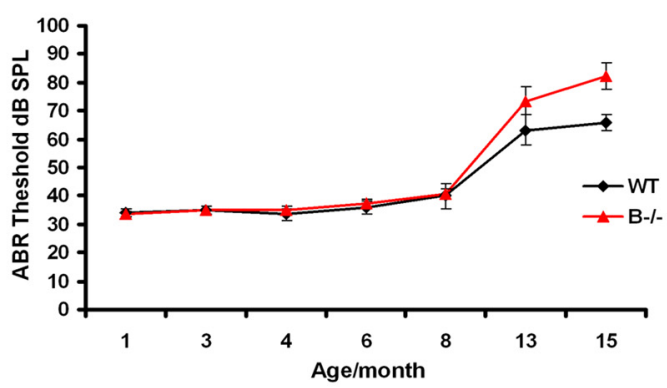

E ABR Wave I Amplitude in SapB mice at P8mo

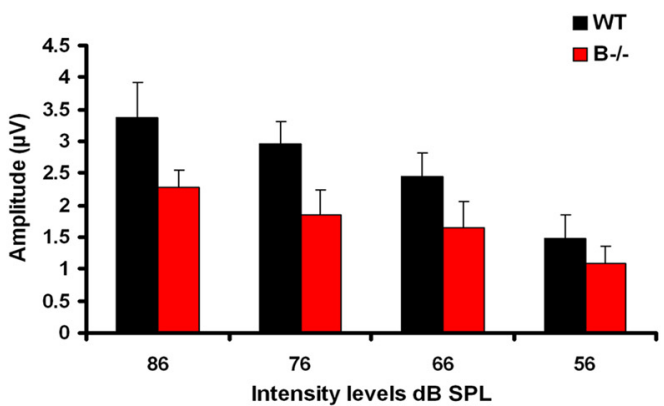

B
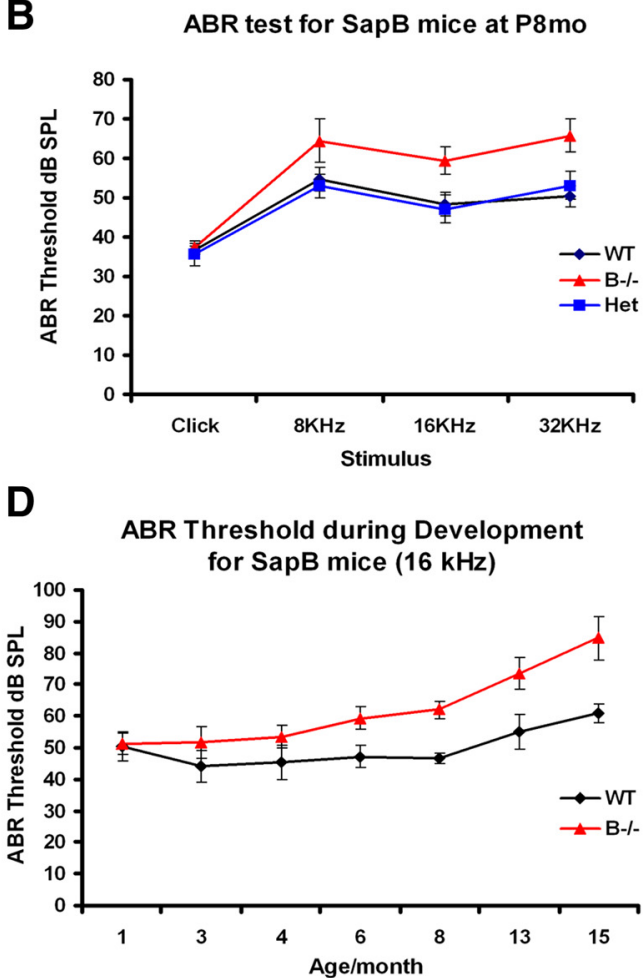

$\mathbf{F}$

Interpeak latency (P2-P1) for SapB mice at P8mo

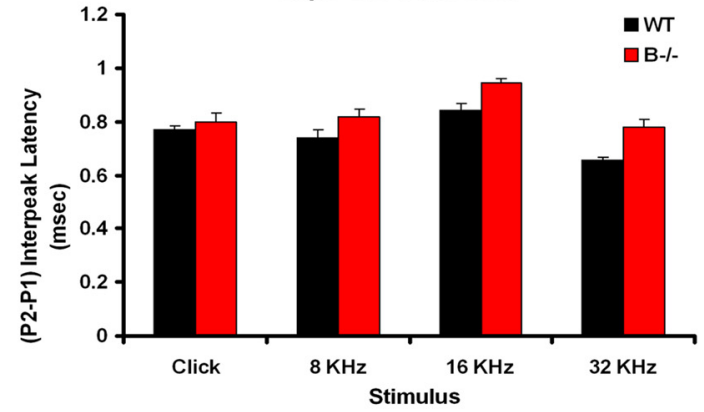

Figure 4. ABR measurement of $\mathrm{B}^{-1-}$ mice. ABR was used to test hearing in $\mathrm{B}^{-1-}$, Het, and WT mice at varying ages (P1mo, P3mo, P4mo, P6mo, P8mo, P13mo, and P15mo) using broadband clicks and tone-burst stimuli $(8,16$, and $32 \mathrm{kHz}) \cdot A$, At P4mo, ABR thresholds demonstrate no significant differences in hearing between the $B^{-1-}(n=10)$, Het $(n=12)$, and WT $(n=15)$ mice. $B$, At P8mo, significant increases in the ABR threshold for each of the tone-burst stimuli $(8,16$, and $32 \mathrm{kHz})$ are noted, though click responses are not significantly different at this age. $\boldsymbol{C}$, There are no differences seen in click stimuli between WT and $B^{-1-}$ mice until P13mo. Afterward the $B^{-1-}$ auditory thresholds become significantly elevated. $\boldsymbol{D}$, In contrast to click stimuli, the frequency-specific ABR thresholds are significantly elevated at P6mo and older for each of the sound stimuli ( 8,16 , and $32 \mathrm{kHz}$; only $16 \mathrm{kHz}$ is shown). $\boldsymbol{E}$, There is a significant decrease in ABR wave I amplitudes in the $B^{-1-}$ mice measured at different intensity levels $(86,76,66$, and $56 \mathrm{dBSPL}$ ) when compared with the WT littermates (Fig. $4 E$ ), likely as a consequence of the reduction in auditory neurons. $\boldsymbol{F}$, ABR P2-P1interpeak latencies showed a small but significant increase at P8mo between $B^{-1-}$ and WT mice.

would also affect the general neuronal output. At P8mo, $\mathrm{B}^{-1-}$ cochlear whole mounts of the base, midturn, and apex stained with myosin 7a, a marker for hair cells, demonstrated normal numbers of OHCs. Additional labeling with phalloidin, a stain for actin, also revealed that $\mathrm{OHC}$ stereocillia and cuticular plates were present and intact (Fig. 5E). Based upon these results, there does not appear to be a defect in $\mathrm{OHC}$ or efferent function through $\mathrm{P} 8 \mathrm{mo}$, despite the loss of $\sim 50 \%$ of the SG neurons at this same age.

\section{Vestibular analysis}

To investigate whether the degenerative changes observed in the cochlea also affected the vestibular system, Scarpa's ganglia and the vestibular fibers of the crista ampullaris (ampulla) were similarly studied at various ages and compared with WT littermates. The overall appearance and organization of the $\mathrm{B}^{-1-}$ ampulla appeared unaltered, including normal hair cells and supporting cell numbers and appearance, with no noticeable vestibular fiber loss in older ages when compared with WT littermates (Fig. 6A). At P15mo, at a time when significant loss of SG neurons is evident, there is very little loss of vestibular nerve fibers, despite the presence of inclusion bodies (Fig. $6 A$, black arrows). Figure $6 B$ demonstrates that similar inclusion bodies observed in SGs were also observed in Scarpa's ganglia of the $\mathrm{B}^{-/-}$mouse, though not nearly as dramatic and causing significantly less damage.

To test whether these modest histologic changes resulted in any functional loss, the swim test was used to measure the ability of the $\mathrm{B}^{-1-}$ mouse to orient in a head-up position and swim 
A DPOAE test for Sap B mice at P4mo
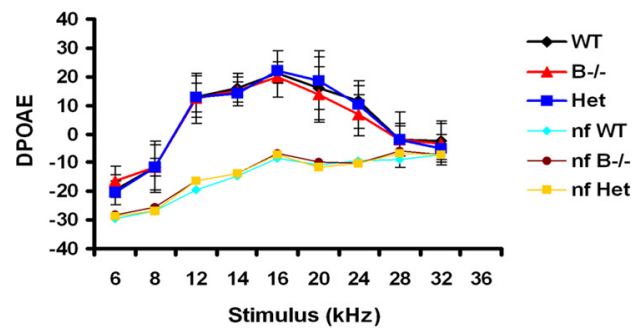

C DPOAE CS test for Sap B mice at P4mo

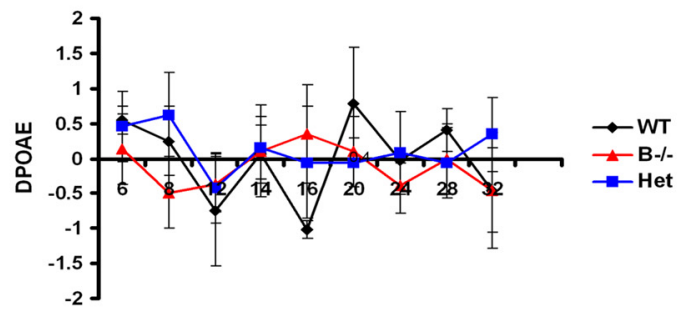

Stimulus (kHz)

\section{B DPOAE test for Sap B mice at P8mo}

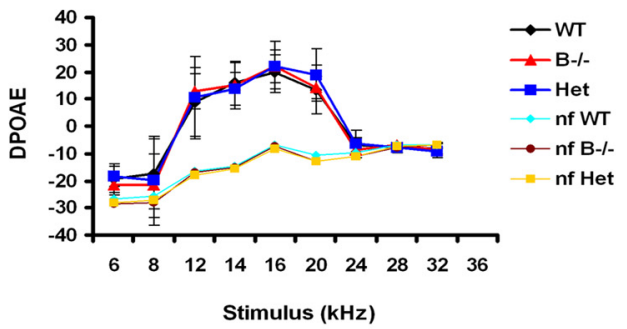

D DPOAE CS test for Sap B mice at P8mo

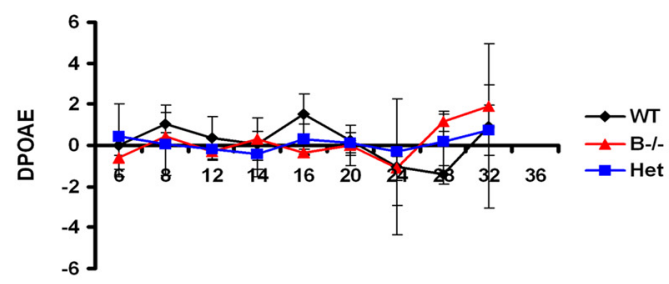

Stimulus (kHz)
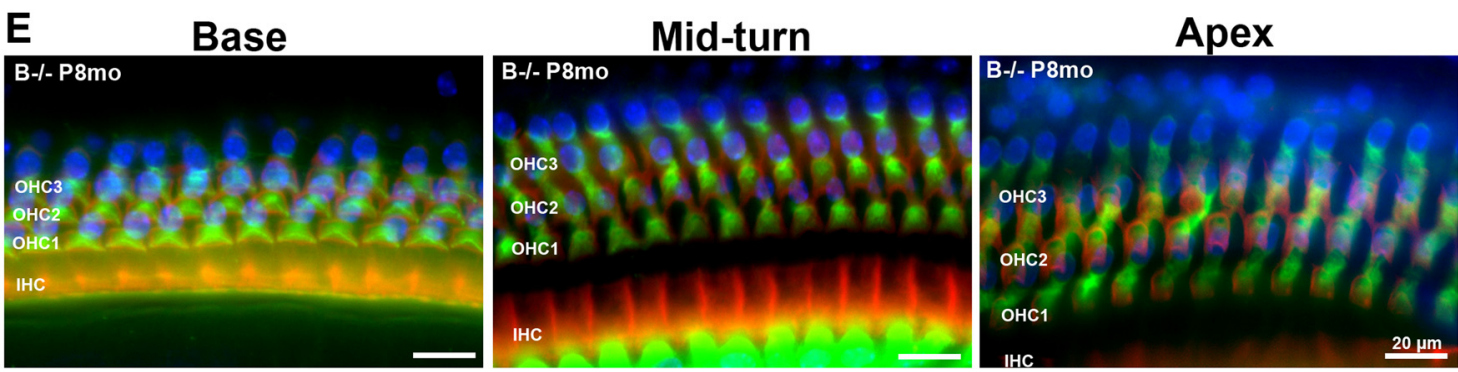

Figure 5. $\mathrm{OHC}$ and efferent function of $\mathrm{B}^{-1-}$ mice. $A-E, O H C$ and efferent auditory function in $B^{-1-}$ mice were measured using DPOAE $(A, B), C S-D P O A E(C, D)$, and cochlear whole-mount immunofluorescent staining using anti-myosin 7 a antibody and rhodamine phalloidin staining $(\boldsymbol{E})$. At P4mo, DPOAE (A) and CS-DPOAE (C) demonstrate no significant differences between WT and $B^{-1-}$ mice. Likewise, at P8mo, no differences are noted in these measures in WT and $B^{-1-}$ mice $(\boldsymbol{B}, \boldsymbol{D})$. $\boldsymbol{E}$, Hair cell counts using representative samples of surface preparations show a normal complement of $\mathrm{OHC}$ and no $\mathrm{OHC}$ loss at all locations along the cochlea. Scale bar, $20 \mu \mathrm{m}$. $\mathrm{OHC}$ rows $1-3$ are indicated by $\mathrm{OHC1,} \mathrm{OHC}$, and $\mathrm{OHC}$, respectively.

comfortably for a full $60 \mathrm{~s}$ (data not shown; Sawada et al., 1994). All $\mathrm{B}^{-1-}$ mice were able to swim and orient properly in water, indistinguishable from WT mice, and able to keep their heads above water for the full $60 \mathrm{~s}$ during all three trials.

More detailed analysis of the vestibular system was obtained by studying VsEPs. Interestingly, despite the modest histologic changes and normal swim test, Figure $6 C, D$ shows that the responses were completely absent from all $\mathrm{B}^{-1-}$ mice that were tested. No measurable responses were observed even at the highest stimulus level ( $+6 \mathrm{~dB}$ re: $1.0 \mathrm{~g} / \mathrm{ms})$. In contrast, normal vestibular function was observed in WT mice as expected. The control group had a mean VsEP threshold of $-9.3 \pm 1.5 \mathrm{~dB}$ (re: $1.0 \mathrm{~g} / \mathrm{ms}), \mathrm{P} 1$ peak latency of $1.36 \pm 0.03 \mathrm{~ms}$, and $\mathrm{P} 1-\mathrm{N} 1$ amplitude of $0.65 \pm 0.07 \mu \mathrm{V}$. Together, these results demonstrate that $\mathrm{B}^{-1-}$ mice present a significant vestibular dysfunction caused by the degeneration of the Scarpa's ganglion neurons and the vestibular nerve fibers.

\section{Sulfatide analysis}

Alcian blue stain, which detects acidic sulfated lipids, was used to assess sulfatide accumulation in cochlear sections of the $\mathrm{B}^{-1-}$ and WT littermates. This test has previously been shown to be abnormal in other organs of $\mathrm{B}^{-1-}$ mice (Sun et al., 2008). In the cochlea of $\mathrm{B}^{-1-}$ mice, a significant increase in alcian blue staining was noted in the SGs (Fig. 7A), indicative of sulfatide accumulation. Further analysis of sulfatide accumulation was performed by liquid chromatography/tandem mass spectrometry (Fig. $7 B-E$ ). For these studies, SG neurons within Rosenthal canals from P6mo B ${ }^{-/-}$and WT mice were pooled for lipid extraction and analysis. Levels of most NFA sulfatide and HFA sulfatide (Fig. $7 B$ ) species significantly increased in $\mathrm{B}^{-1-}$ mouse SGs compared with WT mouse SGs. Both the total NFA sulfatide and HFA sulfatide levels increased in $\mathrm{B}^{-1-}$ mouse SGs by 1.74 -fold and 1.44 -fold, respectively, compared with the WT mouse SGs. On the other hand, total ceramide levels (Fig. 7C) showed no significant increase in the $\mathrm{B}^{-1-}$ SGs when compared with the WT SGs. When sulfatide levels were normalized by $\mathrm{C} 18$ ceramide in the same sample (Fig. $7 D, E$ ), NFA sulfatide species increased dramatically by 3.5 -fold. Total sulfatide levels in $\mathrm{B}^{-1-}$ SGs increased by 1.65 -fold compared with WT SGs, consistent with the increased alcian blue staining seen in SG cochlea sections (Fig. $7 A)$. 


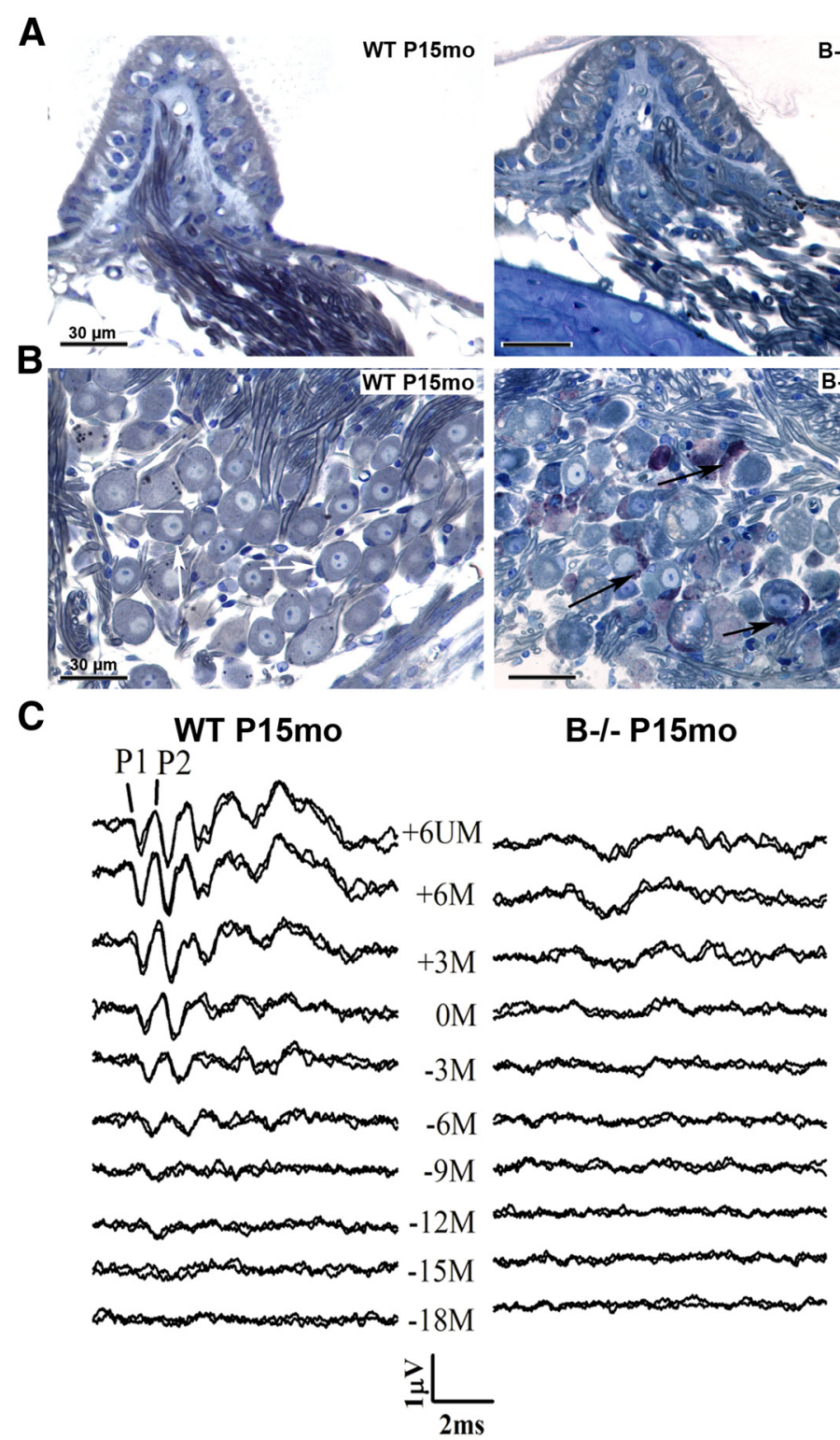

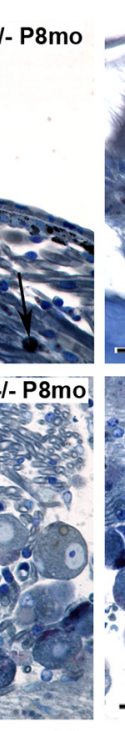

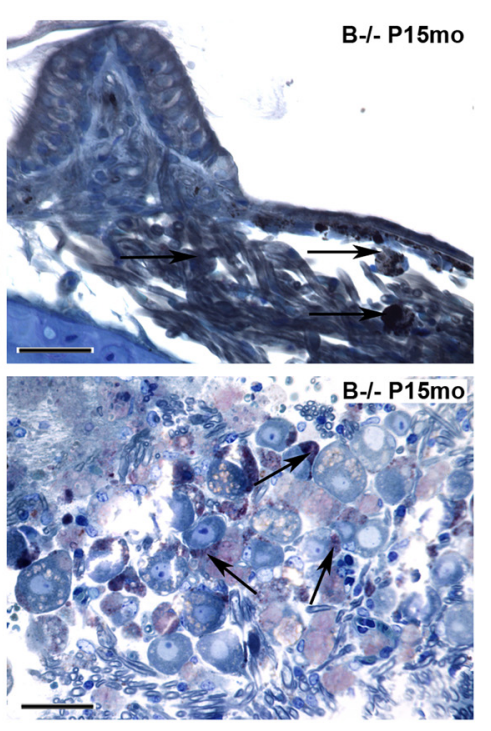

D

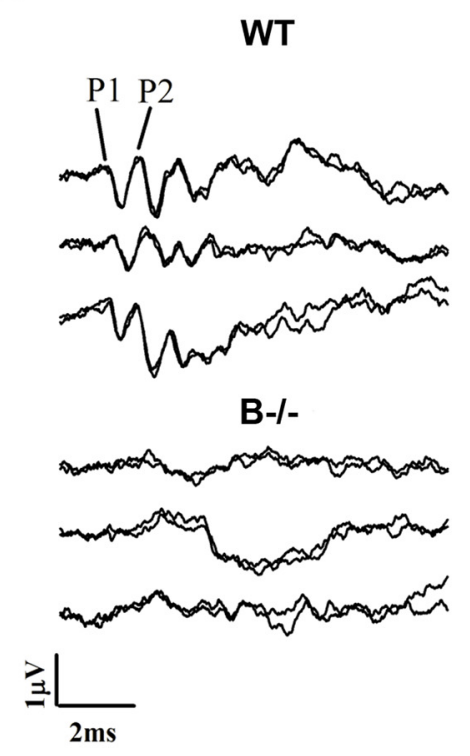

Figure 6. Vestibular function in $B^{-1-}$ mice. $A-D$, Light microscopy of the ampullae nerve fibers $(\boldsymbol{A})$, vestibular ganglion neurons $(\boldsymbol{B})$, and the VsEP recordings $(\boldsymbol{C}, \boldsymbol{D})$ of $B^{-1-}$ mice during development. $\boldsymbol{A}$, The general organization of the ampulla appears unaltered (normal hair cell and supporting cell morphology) with no noticeable vestibular fiber loss in $B^{-1-}$ mice at older ages when compared with WT mice. At P8mo-P15mo, inclusion bodies are seen (black arrows) though there is not an accompanying loss of vestibular neurons. Scale bar, $30 \mu \mathrm{m}$. $\boldsymbol{B}$, Vestibular ganglion of $^{-1-}$ mouse shows the same inclusion bodies as the cochlea SG but with less degeneration from P8mo to P15mo. Scale bar, $30 \mu \mathrm{m}$. C, Representative VsEP intensity series for WT (left) and B ${ }^{-I-}$ (right) mice. The first two positive response peaks are labeled P1 and P2, respectively. Stimulus levels are shown in decibels (re: $1.0 \mathrm{~g} / \mathrm{ms})$ and ranged from $+6 \mathrm{~dB}$ to $-18 \mathrm{~dB}$. At $+6 \mathrm{~dB}, \mathrm{VsEPs}$ were collected without the forward masker (UM) and later with the masker (M) throughout the testing. Each stimulus level shows two response waveforms to demonstrate response replication. As the stimulus level is reduced, peak-to-peak amplitudes decrease and latencies increase until no response is observed at levels below threshold. VsEP thresholds for these representative animals were scored at $-13.5 \mathrm{~dB}$ re: $1.0 \mathrm{~g} / \mathrm{ms}$ for WT and absent response for $B^{-1-}$. Total time represented for each waveform is $10 \mathrm{~ms}$. D, Representative VsEP waveforms recorded at the maximum stimulus level (+6 dB re: $1.0 \mathrm{~g} / \mathrm{ms}$ ) for three WT (top) and three $B^{-1-}$ (bottom) mice. WT mice showed normal vestibular function, and VsEPs were completely absent from $B^{-1-}$ mice. The first two response peaks are labeled $\mathrm{P} 1$ and $\mathrm{P} 2$, respectively. Two waveforms are shown for each animal to demonstrate response replication. Total time represented for each waveform is $10 \mathrm{~ms}$.

\section{Discussion}

This study demonstrates that absence of Sap B function in the inner ear results in progressive accumulation of sulfatides in the satellite cells surrounding SG neurons, followed by degeneration of the satellite cells and loss of the myelin sheath surrounding the type I SG neurons, and finally death of the SG neurons themselves with a resulting loss of hearing. Histological evidence of the SG degeneration is seen as early as $\mathrm{P} 4 \mathrm{mo}$, but becomes much more evident at P8mo and beyond (Fig. 1A). The vestibular system, while still demonstrating sulfatide accumulation, has a milder phenotype with less neuronal loss but severe physiologic dysfunc- tion as demonstrated by absent VsEPs. This represents a marked difference compared with the severe changes seen in the prosaposin KO mouse (Akil et al., 2006), which demonstrated normal SG cell counts, deafness by P25mo, and death by P30mo.

A central feature of the degeneration was the progressive accumulation of inclusion bodies in the satellite cells surrounding the SG neurons, visible from P1mo onwards. These included NFA sulfatides and HFA sulfatides, intermediate metabolites of GSL processing (Fig. 7). In the GSL-degradation pathway, ceramides are derived from sphingomyelin, glucosylceramide, and galactosylceramide that is downstream from sulfatide. Accumu- 
A

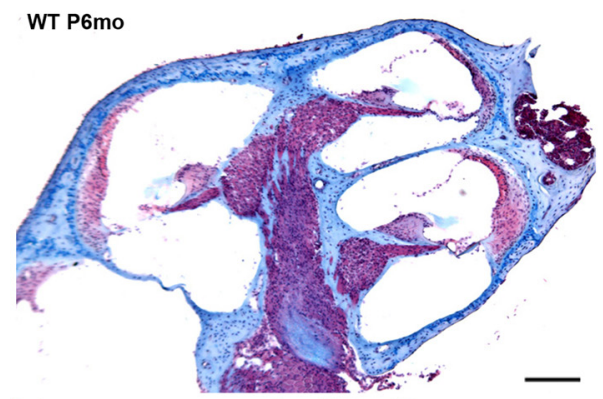

B-I- P6mo
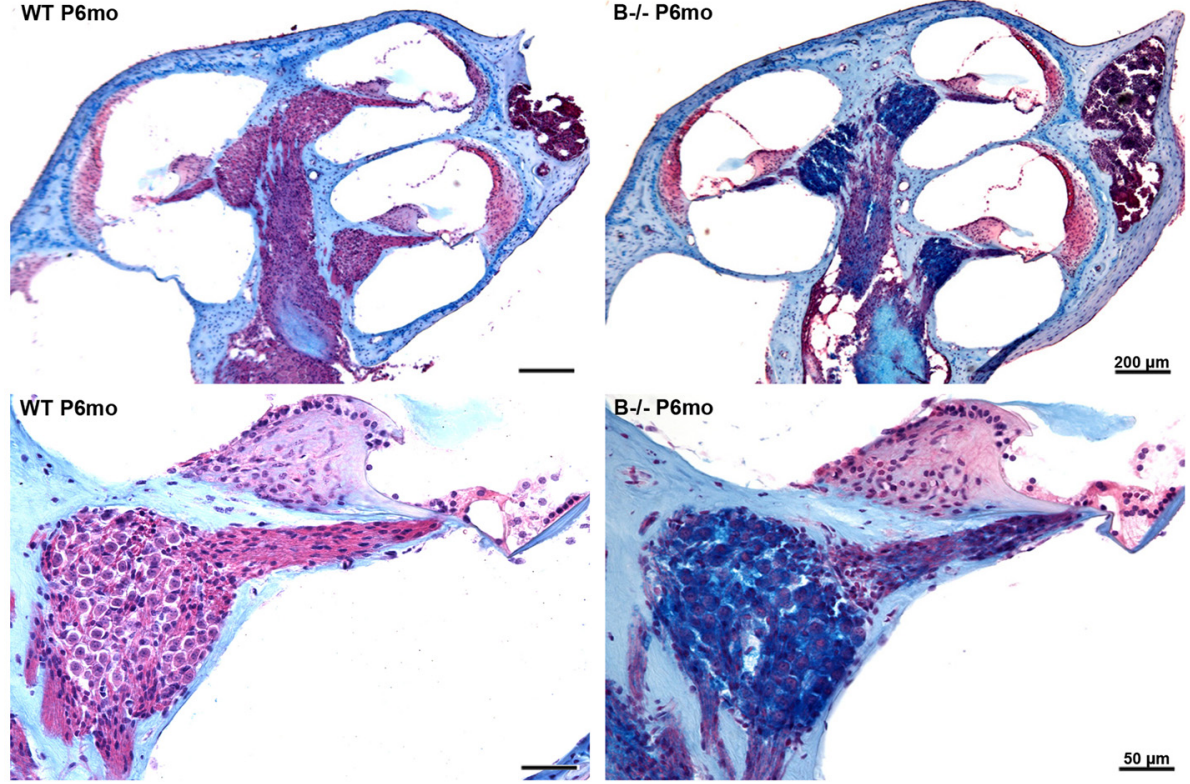

\section{Sulfatide}
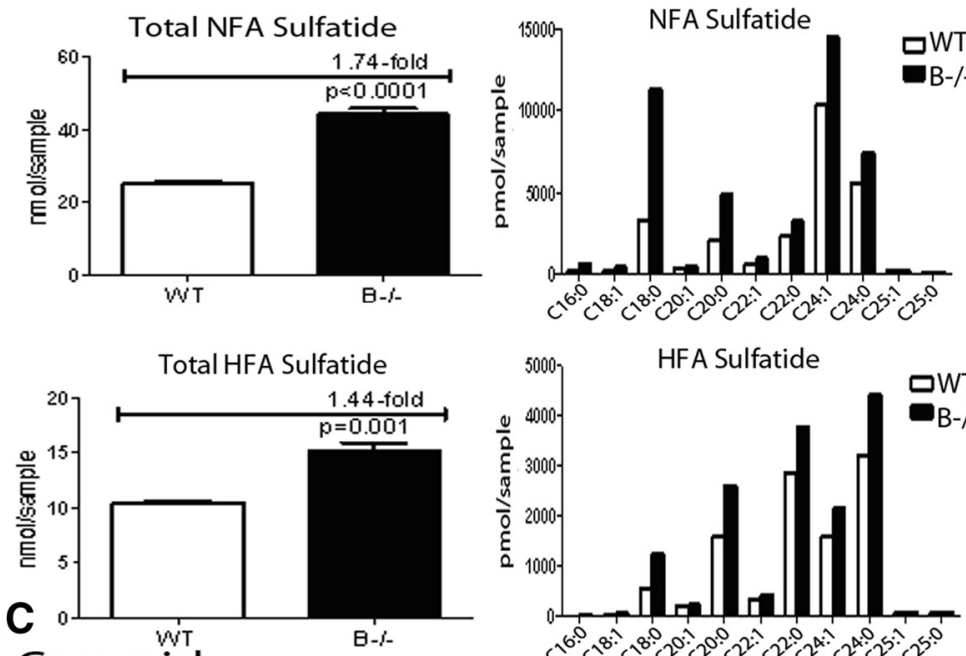

Ceramide
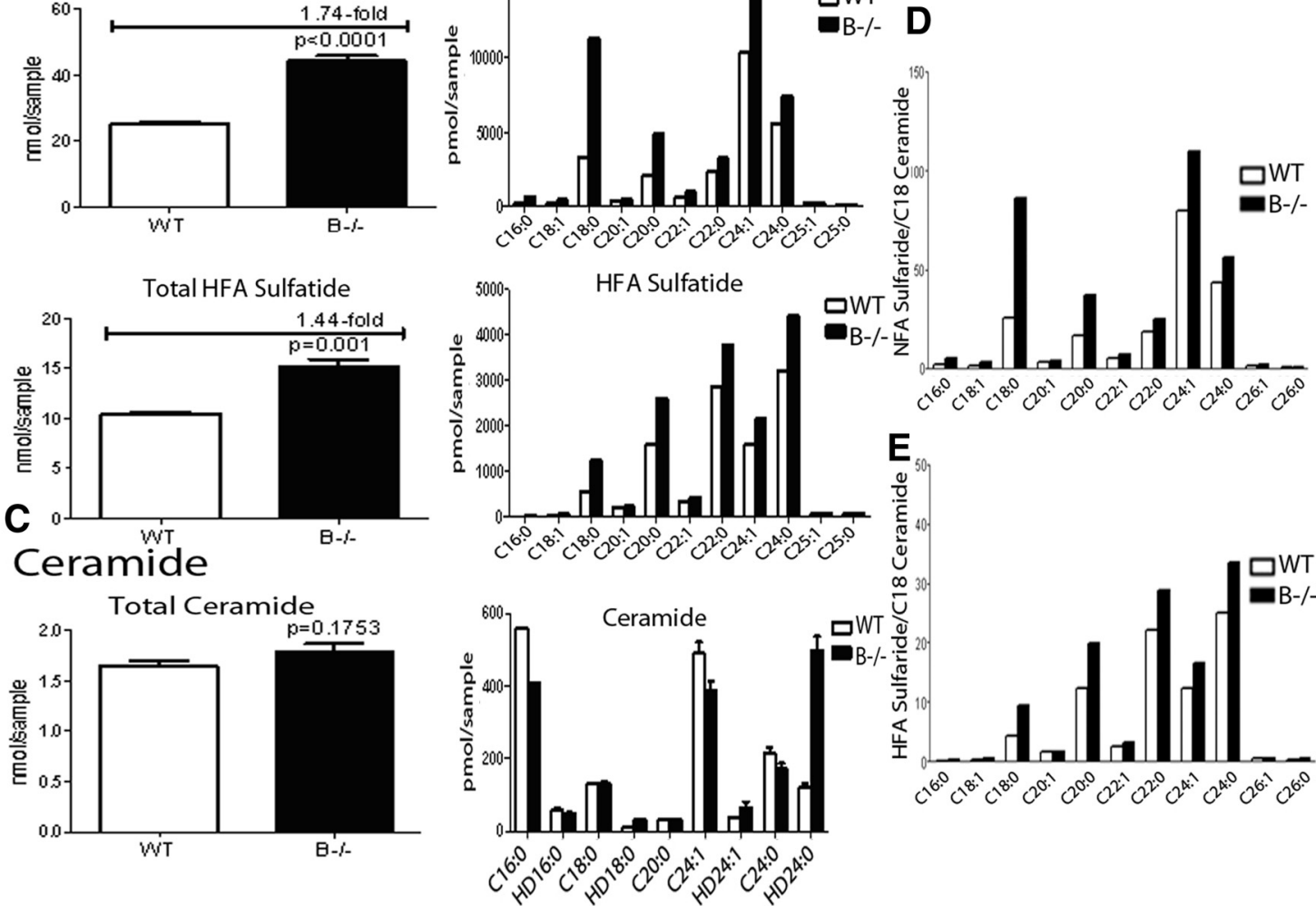

Figure 7. Liquid chromatography/mass spectrometry analysis of sulfatide levels in $\mathrm{B}^{-1-}$ cochlear SGs. $A$, Significant alcian blue staining of the $\mathrm{B}^{-1-}$ cochlear SGs (blue stain) is seen when compared with the WT cochlear SGS, indicative of sulfatide accumulation in SG neurons of $B^{-1-}$ mice. The whole cochlear section (top, low magnification; scale bar, $200 \mu \mathrm{m}$ ) and a higher magnification of the SGs (bottom; scale bar, $50 \mu \mathrm{m}$ ) are shown. $B$, Most of the NFA sulfatide (top) and HFA sulfatide (bottom) species were increased in B ${ }^{-1-}$ mouse SGs compared with WT mouse SGs. Total NFA sulfatides and HFA sulfatides were increased in $B^{-1-}$ mouse SGs by 1.74-fold and 1.44-fold, respectively, when compared with that of WT mice SGs. C, C18 ceramide and total ceramides show no significant increase in the $B^{-1-}$ SGs when compared with that of WT SGS. D, Most NFA sulfatides are increased when normalized to $C 18$ ceramide in the same sample. $\boldsymbol{E}$, Most HFA sulfatide species are also significantly increased when normalized to C18 ceramide in the same sample. Total sulfatides in B ${ }^{-1-}$ SGs were increased by 1.65 -fold compared with WT SGS, mirroring the increased alcian blue staining on SGs in cochlea $(\boldsymbol{A})$.

lation of sulfatides could decrease galactosylceramide, but ceramides may not be affected because their levels can be balanced from sphingomyelin and glucosylceramide pathways. Further, it has been previously reported that galactosylceramide is not sig- nificantly altered in the sap B-deficient mouse brain (Sun et al., 2013) and ceramide is also not altered. Thus, the results in the ear conform to what was seen in the brain. Paralleling the progressive sulfatide accumulation was satellite cell degeneration starting af- 
ter P4mo. These changes mirror those seen not only in the ASAdeficient mice but also in pathologic specimens from humans with MLD (Hess et al., 1996).

While the overall pattern of SG degeneration seen in $\mathrm{B}^{-1-}$ mice resembled that seen in ASA-deficient mice, the latter showed more severe alterations of SG neurons at a much earlier time point, between 4 and 8 months (Coenen et al., 2001). Similar milder findings have been noted for other organs in $\mathrm{B}^{-/-}$mice compared with ASA-deficient mice (Sun et al., 2008). Reasons for these differences are unknown. However, one possible reason could be a lack of alternative ASA-independent pathways for sulfatide metabolism (Sundaram et al., 1995). Another possible reason may have to do with Sap B deficiency, which may result in the accumulation of fewer GSLs than in ASA-deficient mice. It is also possible that despite undetectable levels of Sap B, there may be some residual Sap B function based on the nature of the mutation (absence of the disulfide bond). However, we feel this is unlikely given the dependence on this bond for function, and given evidence from prior studies demonstrating lack of Sap B activity in this model. Comparative quantitative analysis of sulfatide accumulation between these two models could help answer this question. The pattern of hearing loss contrasting the ASA-deficient and the $\mathrm{B}^{-/-}$mice mirrored the morphologic differences seen. In the ASAdeficient mice, the loss of ABR threshold shifts occurred at an earlier age, was more severe, and closely paralleled the deterioration of the SG cells and nerve fibers (D'Hooge et al., 1999). For example, in the $\mathrm{B}^{-/-}$mice, at $\mathrm{P} 15 \mathrm{mo}$, with $\sim 15 \%$ survival of the cochlear SG neurons, the click ABR threshold increased by $15 \mathrm{~dB}$; by comparison, the ASA-deficient mice lost most of their SG cells and had absent ABR thresholds by this same age (Hess et al., 1996).

Another important finding in this study was in the nature of the changes to the myelin sheath of the SG neurons. As evidenced by light microscopy and EM (Figs. 1, 3), the myelin surround the degenerating $S G$ neurons in the $\mathrm{B}^{-1-}$ mice were either absent or quite thinned (Figs. $1 C, 3 A, B$ ). In contrast, in the cochlea of ASA-deficient mice, the degenerating spiral perikarya and axons were surrounded by intact satellite and Schwann cells and structurally normal myelin sheaths (Coenen et al., 2001). Sap B thus appears to play a more critical role in the maintenance of the myelin sheath than ASA in these neuronal subtypes. Further, most of the surviving neurons in the older $\mathrm{B}^{-1-}$ mice proved to be small, primarily nonmyelinated type 2 ganglion cells, which are known to represent a small minority (5-10\%) among the SG cells of normal animals (Jagger and Housley, 2003). The small diameter and the absence of a compact myelin sheath served to identify these surviving neurons as type 2 cells (Fig. 1C, P15mo, arrowheads).

Interestingly, despite severe progressive neuronal degeneration seen in these $\mathrm{B}^{-1-}$ mice, all measures of efferent function were normal, including DPOAEs, CS-DPOAEs, and OHC counts, through P8mo (Fig. 5). The medial olivocochlear (MOC) efferent auditory neurons are myelinated, while the lateral olivocochlear (LOC) neurons are not (Liberman and Brown, 1986). Thus, one would expect, if similar degenerative phenomenon were occurring in this system, that the MOC system would be impaired while the LOC would be intact. The intact efferent response thus suggests several possibilities: the efferent system may be more robust than the afferent neuronal system to loss of Sap B, and/or efferent neurons employ alternative metabolic pathways for GSL metabolism that allowed them to be spared the changes seen with the afferent system. Along similar lines, the dorsal root ganglia in $\mathrm{B}^{-1-}$ mice and other Sap $\mathrm{KO}$ mice have also been noted to have inclusions, but motor neurons are generally not affected by these changes (Sun et al., 2007, 2008), again suggesting alternative manifestations of Sap function in afferent versus efferent neurons.

It is interesting to note that in contrast to the striking histological changes seen in the $\mathrm{B}^{-/-}$mouse, ABR threshold shifts were mild initially and did not progress until much later in the disease process. At $\mathrm{P} 4 \mathrm{mo}$, ABR thresholds demonstrated no significant differences among the $\mathrm{B}^{-/-}$, Het, and WT mice (Fig. $4 A$ ), at a time when SG degeneration was beginning and the satellite cell inclusions were developing. By P8mo, however (Fig. $4 B$ ), a significant increase of ABR thresholds was observed for each of the tone-burst stimuli $(8,16$, and $32 \mathrm{kHz})$, though significant shifts in ABR click responses were not seen until P13mo (Fig. 4C). This overall preservation of click responses in the face of significant neuronal degeneration until the most advanced stages of decline mirrors results seen in mouse models of hearing recovery after noise exposure (Kujawa and Liberman, 2009; Lin et al., 2011), in which even "reversible" noise exposure with recovery of auditory thresholds leads to long-term afferent nerve terminal degeneration while retaining "normal" auditory thresholds. A similar phenomena was observed in a previous study involving virally mediated hearing rescue in the vesicle glutamate transporter 3 KO (VGLUT3 KO) mouse (Akil et al., 2012). In these studies, viral delivery at postnatal day (P) 10-P12 caused VGLUT3 expression in only $40 \%$ of IHCs, yet this was enough to restore ABR thresholds to WT levels for click responses and to near normal levels for pure-tone thresholds. These and similar studies further support the notion that the ABR threshold analysis is an incomplete measure of cochlear health.

Last, we observed a large discrepancy between the phenotypic and physiologic effects from the loss of Sap B function in the vestibular system. The general structure of the vestibular ganglion was slightly altered in the $\mathrm{B}^{-/-}$mouse with less damage to Scarpa's ganglia neurons, despite the presence of similar inclusion bodies that were seen in SG satellite cells (Fig. 6B). Despite these mild changes, VsEPs documented a complete loss of vestibular function. The nature of this discrepancy remains unclear. It is known that a variety of lesions to the inner ear, including damage from surgical, acoustic, or ototoxic trauma, often affects the cochlea to a greater degree than the vestibular system (Spoendlin, 1975; Hoeffding and Feldman, 1988). However, in many of these models, it is the hair cells and supporting cells that are initially damaged, followed by secondary neuronal degeneration, whereas in the $\mathrm{B}^{-/-}$mice, these former structures are all normal. Again, the apparent vulnerability of the myelinated SG neurons to loss of Sap B function may be playing a role here. As noted by Spoendlin (1971), transection of the vestibular-cochlear nerve leads to the degeneration of myelinated SG neurons and the survival of type 2 SG neurons, the organ of Corti, and the vestibular ganglion. This implies that the phylogenetically older vestibular ganglion neurons are not as sensitive to changes in myelin metabolism. Another clue comes from comparisons with the ASA-deficient mice, where the storage material did accumulate in the vestibular hair cell, and was accompanied by degeneration of vestibular ganglion neurons (Coenen et al., 2001), whereas in the $\mathrm{B}^{-l-}$ mice here, the vestibular epithelium was intact and the storage material was not seen accumulating in the vestibular hair cells.

\section{Conclusion}

Sap B is an essential activator protein for ASA in the hydrolysis of sulfatide, a critical lipid component of myelin. Within the ear, though deficiency of Sap B leads to sulfatide accumulation in satellite cells, causing SG and vestibular ganglion degeneration, 
only the myelinated SG neurons undergo large-scale neuronal degeneration, in turn leading to hearing loss and vestibular dysfunction. Nonmyelinated fibers in the SG are spared, preserving the efferent system. Our findings show that Sap B deficiency, though not as severe as a deficiency of ASA, nonetheless mimics the pathologic changes seen in human MLD-related diseases.

\section{References}

Ahn VE, Faull KF, Whitelegge JP, Fluharty AL, Privé GG (2003) Crystal structure of saposin B reveals a dimeric shell for lipid binding. Proc Natl Acad Sci U S A 100:38-43. CrossRef Medline

Akil O, Chang J, Hiel H, Kong JH, Yi E, Glowatzki E, Lustig LR (2006) Progressive deafness and altered cochlear innervation in knock-out mice lacking prosaposin. J Neurosci 26:13076-13088. CrossRef Medline

Akil O, Seal RP, Burke K, Wang C, Alemi A, During M, Edwards RH, Lustig LR (2012) Restoration of hearing in the VGLUT3 knockout mouse using virally mediated gene therapy. Neuron 75:283-293. CrossRef Medline

Berglund AM, Ryugo DK (1991) Neurofilament antibodies and spiral ganglion neurons of the mammalian cochlea. J Comp Neurol 306:393-408. CrossRef Medline

Ciaffoni F, Tatti M, Boe A, Salvioli R, Fluharty A, Sonnino S, Vaccaro AM (2006) Saposin B binds and transfers phospholipids. J Lipid Res 47:10451053. CrossRef Medline

Coenen R, Gieselmann V, Lüllmann-Rauch R (2001) Morphological alterations in the inner ear of the arylsulfatase A-deficient mouse. Acta Neuropathol 101:491-498. Medline

Deconinck N, Messaaoui A, Ziereisen F, Kadhim H, Sznajer Y, Pelc K, Nassogne MC, Vanier MT, Dan B (2008) Metachromatic leukodystrophy without arylsulfatase A deficiency: a new case of saposin-B deficiency. Eur J Paediatr Neurol 12:46-50. CrossRef Medline

D’Hooge R, Coenen R, Gieselmann V, Lüllmann-Rauch R, De Deyn PP (1999) Decline in brainstem auditory-evoked potentials coincides with loss of spiral ganglion cells in arylsulfatase A-deficient mice. Brain Res 847:352-356. CrossRef Medline

Hess B, Saftig P, Hartmann D, Coenen R, Lüllmann-Rauch R, Goebel HH, Evers M, von Figura K, D’Hooge R, Nagels G, De Deyn P, Peters C, Gieselmann V (1996) Phenotype of arylsulfatase A-deficient mice: relationship to human metachromatic leukodystrophy. Proc Natl Acad Sci U S A 93:14821-14826. CrossRef Medline

Hoeffding V, Feldman ML (1988) Degeneration in the cochlear nerve of the rat following cochlear lesions. Brain Res 449:104-115. CrossRef Medline

Hulková $\mathrm{H}$, Cervenková $\mathrm{M}$, Ledvinová J, Tochácková M, Hrebícek M, Poupetová $\mathrm{H}$, Befekadu A, Berná L, Paton BC, Harzer K, Böör A, Smíd F, Elleder M (2001) A novel mutation in the coding region of the prosaposin gene leads to a complete deficiency of prosaposin and saposins, and is associated with a complex sphingolipidosis dominated by lactosylceramide accumulation. Hum Mol Genet 10:927-940. CrossRef Medline

Jacobson M, Kim S, Romney J, Zhu X, Frisina R (2003) Contralateral suppression of distortion product otoacoustic emissions declines with age: a comparison of findings in CBA Mice with Human Listeners. Laryngoscope 113:1707-1713. Medline

Jagger DJ, Housley GD (2003) Membrane properties of type II spiral ganglion neurones identified in a neonatal rat cochlear slice. J Physiol 552: 525-533. CrossRef Medline

Jones SM, Erway LC, Bergstrom RA, Schimenti JC, Jones TA (1999) Vestibular responses to linear acceleration are absent in otoconia-deficient C57BL/6JEi-het mice. Hear Res 135:56-60. CrossRef Medline

Jones SM, Erway LC, Johnson KR, Yu H, Jones TA (2004) Gravity receptor function in mice with graded otoconial deficiencies. Hear Res 191:34-40. CrossRef Medline

Khan Z, Carey J, Park HJ, Lehar M, Lasker D, Jinnah HA (2004) Abnormal motor behavior and vestibular dysfunction in the stargazer mouse mutant. Neuroscience 127:785-796. CrossRef Medline

Kishimoto Y, Hiraiwa M, O’Brien JS (1992) Saposins: structure, function, distribution, and molecular genetics. J Lipid Res 33:1255-1267. Medline

Kujawa SG, Liberman MC (2009) Adding insult to injury: cochlear nerve degeneration after "temporary" noise-induced hearing loss. J Neurosci 29:14077-14085. CrossRef Medline

Leake PA, Hradek GT, Hetherington AM, Stakhovskaya O (2011) Brainderived neurotrophic factor promotes cochlear spiral ganglion cell survival and function in deafened, developing cats. J Comp Neurol 519: 1526-1545. CrossRef Medline

Li SC, Sonnino S, Tettamanti G, Li YT (1988) Characterization of a nonspecific activator protein for the enzymatic hydrolysis of glycolipids. J Biol Chem 263:6588-6591. Medline

Liberman MC, Brown MC (1986) Physiology and anatomy of single olivocochlear neurons in the cat. Hear Res 24:17-36. CrossRef Medline

Lim D, Erwy L, Clark D (1978) Tilted-head mice with genetic otoconial anomaly. Behavioral and morphological correlates. In: Vestibular mechanisms in health and disease (Hood D, ed), pp 195-206. London: Academic.

Lin HW, Furman AC, Kujawa SG, Liberman MC (2011) Primary neural degeneration in the Guinea pig cochlea after reversible noise-induced threshold shift. J Assoc Res Otolaryngol 12:605-616. CrossRef Medline

Matsuda J, Kido M, Tadano-Aritomi K, Ishizuka I, Tominaga K, Toida K, Takeda E, Suzuki K, Kuroda Y (2004) Mutation in saposin D domain of sphingolipid activator protein gene causes urinary system defects and cerebellar Purkinje cell degeneration with accumulation of hydroxy fatty acid-containing ceramide in mouse. Hum Mol Genet 13:2709-2723. CrossRef Medline

Mock B, Jones TA, Jones SM (2011) Gravity receptor aging in the CBA/CaJ strain: a comparison to auditory aging. J Assoc Res Otolaryngol 12:173183. CrossRef Medline

Ornitz DM, Bohne BA, Thalmann I, Harding GW, Thalmann R (1998) Otoconial agenesis in tilted mutant mice. Hear Res 122:60-70. CrossRef Medline

Sandhoff K (2001) The GM2-gangliosidoses and the elucidation of the betahexosaminidase system. Adv Genet 44:67-91. CrossRef Medline

Sawada I, Kitahara M, Yazawa Y (1994) Swimming test for evaluating vestibular function in guinea pigs. Acta Otolaryngol Suppl 510:20-23. Medline

Schlote W, Harzer K, Christomanou H, Paton BC, Kustermann-Kuhn B, Schmid B, Seeger J, Beudt U, Schuster I, Langenbeck U (1991) Sphingolipid activator protein 1 deficiency in metachromatic leucodystrophy with normal arylsulphatase A activity. A clinical, morphological, biochemical, and immunological study. Eur J Pediatr 150:584-591. CrossRef Medline

Spoendlin H (1971) Degeneration behaviour of the cochlear nerve. Arch Klin Exp Ohren Nasen Kehlkopfheilkd 200:275-291. CrossRef Medline

Spoendlin H (1975) Retrograde degeneration of the cochlear nerve. Acta Otolaryngol 79:266-275. CrossRef Medline

Sun Y, Qi X, Witte DP, Ponce E, Kondoh K, Quinn B, Grabowski GA (2002) Prosaposin: threshold rescue and analysis of the "neuritogenic" region in transgenic mice. Mol Genet Metab 76:271-286. CrossRef Medline

Sun Y, Witte DP, Zamzow M, Ran H, Quinn B, Matsuda J, Grabowski GA (2007) Combined saposin C and D deficiencies in mice lead to a neuronopathic phenotype, glucosylceramide and alpha-hydroxy ceramide accumulation, and altered prosaposin trafficking. Hum Mol Genet 16: 957-971. CrossRef Medline

Sun Y, Witte DP, Ran H, Zamzow M, Barnes S, Cheng H, Han X, Williams MT, Skelton MR, Vorhees CV, Grabowski GA (2008) Neurological deficits and glycosphingolipid accumulation in saposin B deficient mice. Hum Mol Genet 17:2345-2356. CrossRef Medline

Sun Y, Zamzow M, Ran H, Zhang W, Quinn B, Barnes S, Witte DP, Setchell KD, Williams MT, Vorhees CV, Grabowski GA (2013) Tissue-specific effects of saposin A and saposin B on glycosphingolipid degradation in mutant mice. Hum Mol Genet 22:2435-2450. CrossRef Medline

Sundaram SK, Fan JH, Lev M (1995) A neutral galactocerebroside sulfate sulfatidase from mouse brain. J Biol Chem 270:10187-10192. CrossRef Medline

Von Figura K, Gieselmann V, Jaeken J (2001) Metachromatic leukodystrophy. In: The metabolic and molecular basis of inherited disease (Scriver CR, Beaudet AL, Sly WS, Valle D, eds), pp 3695-3724. New York: McGraw-Hill. 